\title{
Ökologische Untersuchungen an Hydroiden des Felslitorals von Santa Marta (Kolumbien)
}

\author{
E. WEDLER \\ Lebrstubl für spezielle Zoologie der Ruhr-Universität Bochum; \\ Bochum, Bundesrepublik Deutschland
}

\begin{abstract}
Ecological studies on hydroids of the rocky littoral of Santa Marta (Colombia). The ecology of tropic hydroids on the rocky shore of Santa Marta, Colombia, was studied from January 1971 to April 1972. Main interests concentrated on vertical distribution, temporal succession, activity, maturity, population density, shape and growth of colonies, and on type of settlement. These aspects have been related to quantitative data and to variations in biotic and abiotic factors. The results are compared with those obtained on other types of shores, viz. artificial and sandy shores. They indicate that local abiotic differences in water quality are influenced, above all, by the sequence of dry and rainy seasons. In a rapidly changing abiotic environment, life cycles and ontogenetic stages (settlement, growth, maturity) follow each other faster than in a static environment. With increasing water depth, the density of the hydroid populations decreases, while the size of single colonies increases. In addition, with increasing depth, the length of the maturity period increases. For the same species, the time of attainment of maturity may be different in different localities. Hydroid species with short life cycles settle faster than species with long life cycles. Hydroid polyps may counteract environmental perturbations by changes in activity. Distribution and zonation of hydroid populations depend to a high degree on water movement, sun orbit, and shade-spending coastal profiles.
\end{abstract}

\section{EINLEITUNG}

Okologische Beobachtungen und Studien über die Zonierungen der Lebensgemeinschaften im Litoral des mittelamerikanischen Raumes wurden bisher nur in Korallenriffen (u. a. Mergner, 1972; Kühlmann, 1974), im Sandlitoral (Dahl, 1953) und im oberen Felslitoralbereich (u. a. Lewis, 1960; Moкyevski, 1960; Southward, 1958; StePHENSON, 1949) durchgeführt. Diese Untersuchungen stellten jedoch zumeist nur kurze "Momentaufnahmen" innerhalb relativ kleiner Untersuchungsbereiche dar. Außer den Arbeiten von RIEDL (1959) und MERGNer (1967) sind bisher keine weiteren einschlägigen In-situ-Untersuchungen über die Okologie des Hydroidenbewuchses eines Litoralgebietes durchgeführt worden.

Im April und Mai 1967 sammelte Mergner Hydroidpolypen an verschiedenen Litoralabschnitten um Santa Marta (Kolumbien) und charakterisierte die ökologischen Verhältnisse der jeweiligen Fundorte. Die dabei angestellten Beobachtungen bilden die Grundlagen für diese Arbeit.

Sessile Meeresbewohner des Felslitorals zeigen eine beträchtliche Variabilität in bezug auf ihre Form und Verteilung. Dies gilt im besonderen Maße für Hydroid- 
polypen. Abgesehen von den Substratverhältnissen sind für sie die großen Expositionsunterschiede (z. B. für Licht und Wasserbewegung) Grundbedingungen für starke Abweichungen in Form und Verbreitung. Die Klärung dieser Aspekte sowie des jährlichen Aktivitätswechsels und der populationsdynamischen Veränderungen bilden die Hauptthemen der vorliegenden Untersuchungen.

\section{MATERIAL UND METHODE}

Der größte Teil der Hydroidpolypen wurde durch Tauchgänge gesammelt. Hydroiden tieferer Litoralbereiche $(30-200 \mathrm{~m}$ ) wurden zusätzlich durch Dredgen oder aus Netzfängen einiger „Shrimptrawler“ gewonnen.

Das Felslitoral bei Santa Marta ist unmittelbar unterhalb des Instituto ColomboAleman sehr stark gegliedert und zeigt eine Vielfalt an Expositionsverhältnissen. Unter der NW-Pier in der Nähe des Institutes fanden sich dicht gedrängt fast alle in dieser Region vorkommenden Hydroidenarten.

Als Meßgeräte wurden verwendet: Aerometer, Thermometer, Sauerstoff-Temperatursonde nach GRASHOFF, ein eigens entwickeltes Lichtmeßgerät mit Interferenzfilter (mit den Nanometerbcreichen 413, 469, 521, 580, 638, 692 und 746). Zur Registrierung der Besiedlungsfolge wurden verschiedenartige Substrate ausgelegt. Für cine spätere Auswertung wurden Proben der Begleitfauna und -flora fixiert.

Als Bestimmungsliteratur dienten vor allem die Arbeiten von Clarke (1879, 1882), Congdon (1907), Fraser (1944, 1947), Marktanner-Turneretscher (1890), Nutting $(1900,1904$ und 1915), Stechow $(1919,1923)$, Vannucci $(1946,1949)$ und VERVOORT (1968).

\section{TOPOGRAPHIE UND GEOMORPHOLOGIE DES UNTERSUCHUNGSGEBIETES}

Das Untersuchungsgebiet liegt an der karibischen Küste Kolumbiens in der Ungebung von Santa Marta (Abb. 1 und 2). Im SO der Stadt erhebt sich die Sierra Nevada de Santa Marta. Thre Ausläufer treten bis einige Kilometer vor Rio Hacha an die Küste heran und trennen felsige Buchten $a b$, die im Inneren durch Sandstrände $a b-$ geschlossen werden. An den Flanken dieser Buchten finden sich einzelne kleine Korallenriffe. Südlich von Santa Marta bis zur Mündung der Cienaga Grande de Santa Marta erstrecken sich dagegen lange Sandstrände, die nur gelegentlich von Felsklippen unterbrochen werden. Das Felslitoral vor Santa Marta besteht aus metamorphen Gesteinen, u. a. Chloriten, Phylliten und Glimmerschiefer und zum Teil aus verwittertem Granit. Im Sandlitoral der Buchten bilden u. a. Granitblöcke und Strandfels (beach rock) die Hartsubstrate. Etwa $100 \mathrm{~km} \mathrm{SW}$ von Santa Marta mïndet der größte Strom Kolumbiens, der Rio Magdalena, ins Karibische Meer. Er steht über zahlreiche Nebenarme mit der Cienaga Grande de Santa Marta in Verbindung. Die Wassermassen der Mündung werden bei vorherrschender NO-Strömung bis vor Santa Marta gedriftet. 


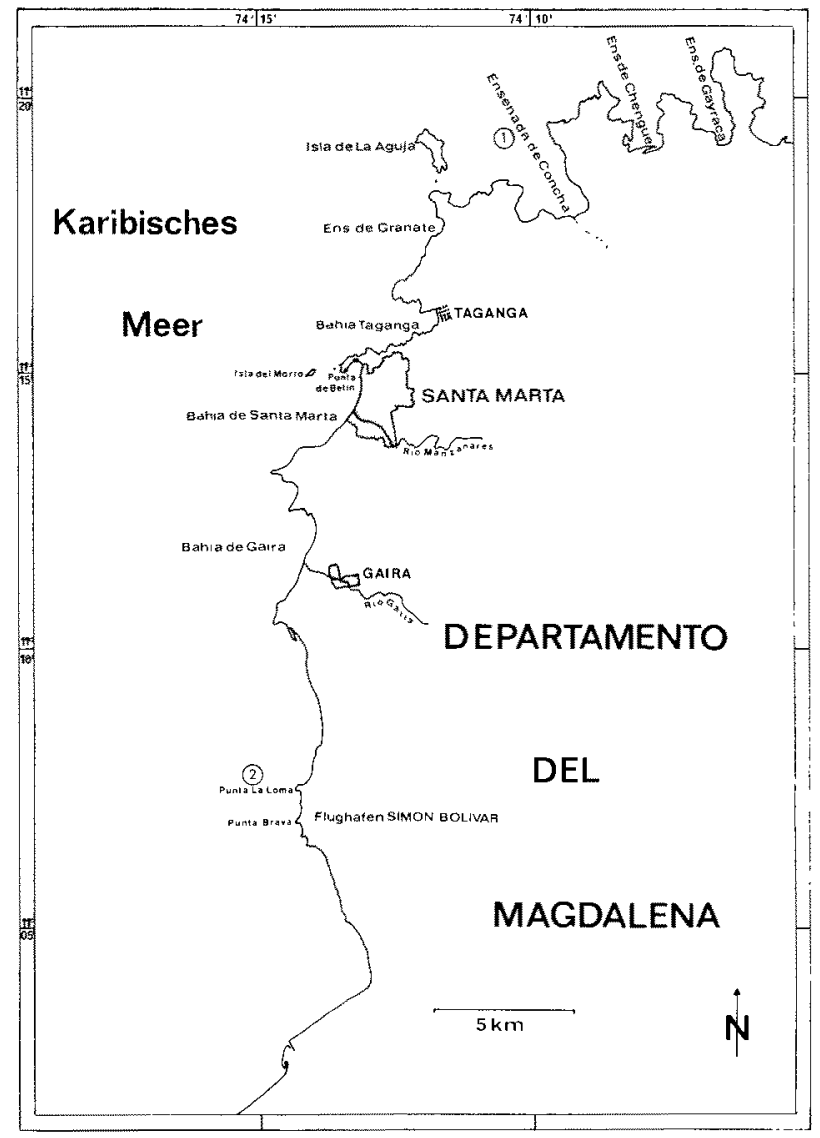

Abb. 1: Untersuchungsregion. Die Nummern 1 und 2 zeigen zwei widhtige Untersudungsstandorte außerhalb von Santa Marta (Kolumbien)

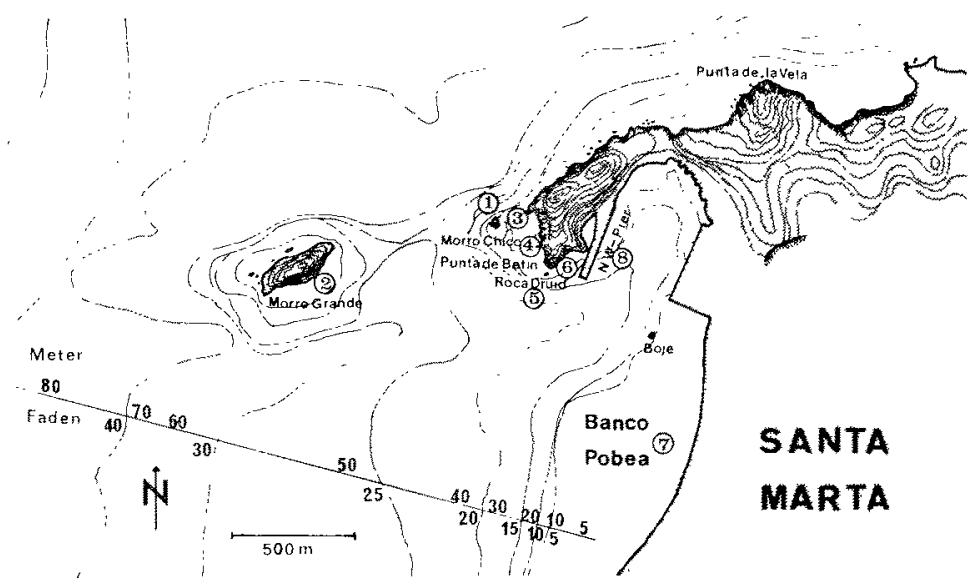

Abb. 2: Hafenbecken von Santa Marta mit der Halbinsel Punta de Betin. (Verändert nach: United States Goverment Chart 1938/64.) Die Nummern 1 bis 8 veranschaulichen die Lage der wichtigsten Untersuchungsstandorte 


\section{ABIOTISCHE NATURVERHALTNISSE}

$\mathrm{K} \mathrm{l}$ im a und Wetter. In der Umgebung von Santa Marta ist das Klima trocken und heiß, mit Ausnahme von kurzen Unterbrechungen in der Regenzeit. Gemildert wird es nur durch den Einfluß des Meeres und den zeitweise sehr starken NOPassat. Die Windverhältnisse in der Region von Santa Marta wurden eingehend von Herrmann (1970) beschrieben. Die Trodkenzeit ist die Zeit des NO-Passates. Ein föhnartiger Fallwind aus der Sierra Nevada wird durch die Düsenwirkung des Manza-

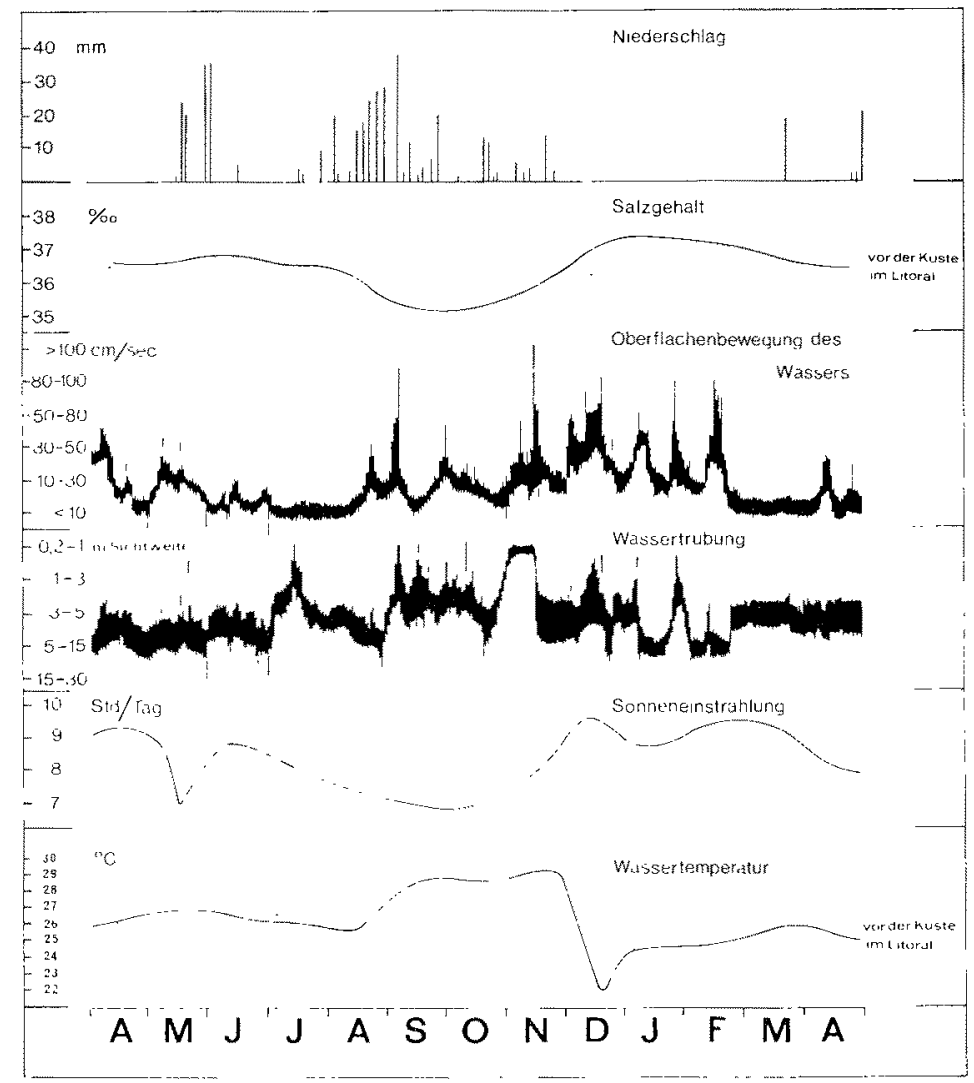

Abb. 3: Verändcrungen abiotischer Faktoren (gemessen vom April 1971 bis zum April 1972)

narestales so stark beschleunigt, daß er zeitweilig Geschwindigkeiten bis mehr als $10 \mathrm{~m} / \mathrm{s}$ erreicht. Dieser orkanartige Wind, der unter anderem über Punta de Betin zicht, wird „Brisa“ genannt und die Zeit, in der er vorherrscht, demzufolge „Brisazeit $^{*}$. In der übrigen Zeit, nämlich von März bis Dezember, weht gewöhnlich von $11.00 \mathrm{~h}$ bis $13.00 \mathrm{~h}$ ein örtlicher Wind aus SWlicher Richtung bis etwa $2-3 \mathrm{sm}$ vom Land. Nach $13.00 \mathrm{~h}$ setzt dann gelegentlich wieder der Passat ein, häufger aber weht der Wind aus Nlicher Richtung. Die Luftemperatur bewegte sich im Laufe des Unter- 
suchungsjahres zwischen $27^{\circ}$ und $28^{\circ} \mathrm{C}$. In der kleinen Trockenzeit (Veranillo de San Juan) erhöhte sie sich auf $28^{\circ}$ bis $29^{\circ} \mathrm{C}$.

Oberflächenbewegung des Wassers. Abbildung 3 verdeutlicht die Bewegungsunterschiede an der Wasseroberfläche der Bahia de Santa Marta im Laufe von 13 Monaten. Danach war das Wasser jeweils zu Beginn der „Brisazeit" am stärksten bewegt. Heftige Bewegungen traten in der Zeit von Dezember bis Februar nur $a b$ und zu auf. Je an einem Tag im September und im November war die Wasseroberfläche vor Punta de Betin orkanartig aufgewühlt. Ursache hierfür waren Ausläufer von Stürmen, deren Zentren weit außerhalb im Karibischen Meer lagen. Durch die

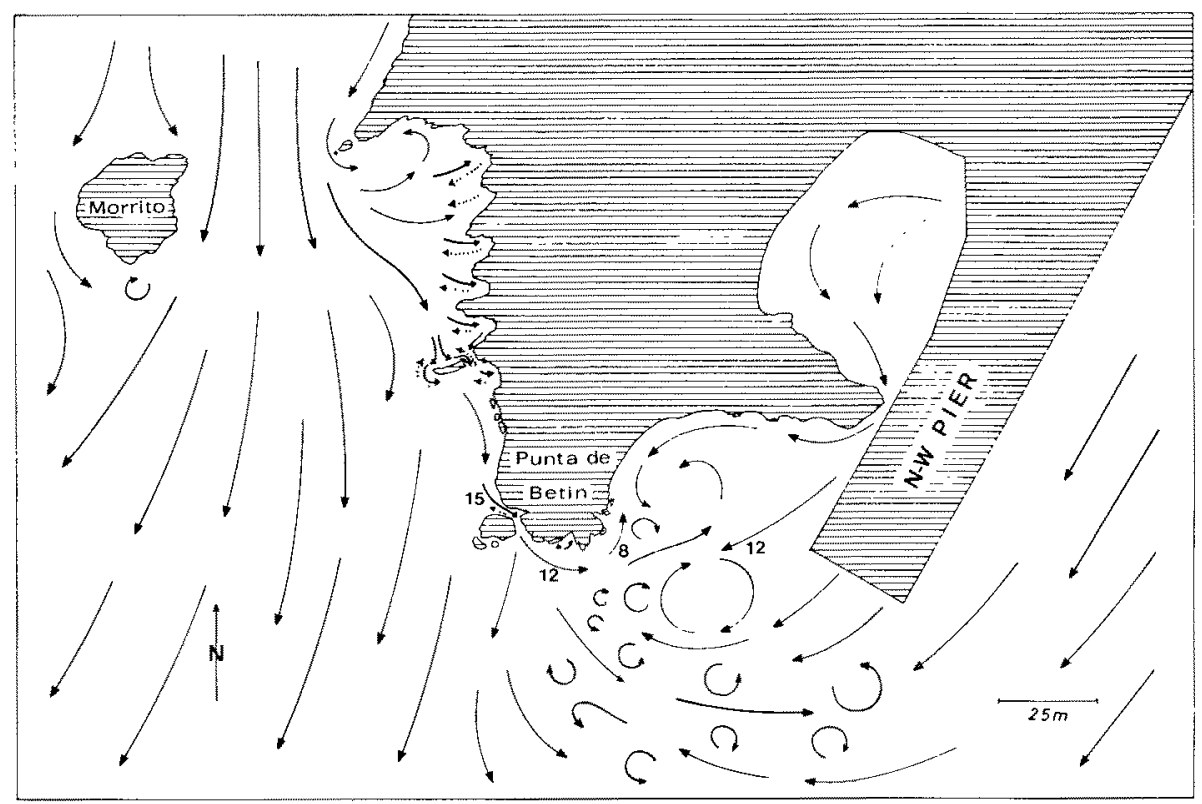

Abb. 4: Strömungsverhältnisse vor der Halbinsel Punta de Betin. Die Zahlen verdeutlichen die Geschwindigkeiten (m/sec) einiger Teilströmungen. (Aufgenommen am 27. 10. 1971 um $16.00 \mathrm{Uhr}$ )

beiden Sturmausläufer wurde an einigen Stellen das Substrat vom Aufwuchs befreit. Es verschwanden in manchen Biotopen für kurze Zeit auch einige stockbildende Hydroiden, während andere Hydroiden - vor allem unter der NW-Pier - von ihrem Epiphyten- bzw. Epizoenüberzug gereinigt wurden.

$S$ t ö m u $\mathrm{n}$ g. Die Strömungen vor Santa Marta werden durch den Nordäquatorialstrom geprägt, der entlang der Küste von Venezuela westwärts in den karibischen Raum eindringt (PrAHM, 1972). Von ihm geht vor dem südlichen Teil Mittelamerikas eine Gegenströmung aus, die sich mit der atlantischen Strömung in der Höhe von Santa Marta triff. Beide beeinflussen abwechselnd den Wassercharakter vor Santa Marta. Oberwiegt die Gegenströmung, dann dringt das von ihr mitgeführte trübe Mündungswasser des Magdalena bis in das Hafenbecken von Santa Marta vor. Die Strömungs- 
verhältnisse vor Punta de Betin in der Bucht von Santa Marta veranschaulicht Abbildung 4.

S a l z g e h a lt. Der größte Teil des Wassers, das den Salzgehalt des Litorals um Santa Marta während der Regenzeit beeinflußt, kommt von den Hängen der Sierra Nevada und aus dem Innern Kolumbiens. Prinzipiell blieben die Salzgehaltwerte im Laufe des Tages und der Nacht konstant. Die aus Abbildung 5 B ersichtlichen Niveauunterschiede in den einzelnen Monaten spiegeln sich auch in der Jahreskurve (vgl. Abb. 3) wider. Während der Regenzeit ging der Salzgehalt jeweils um die Mittagszeit zurück. Diese Schwankung (Abb. 5 B) war charakteristisch für den Wasserkörper um
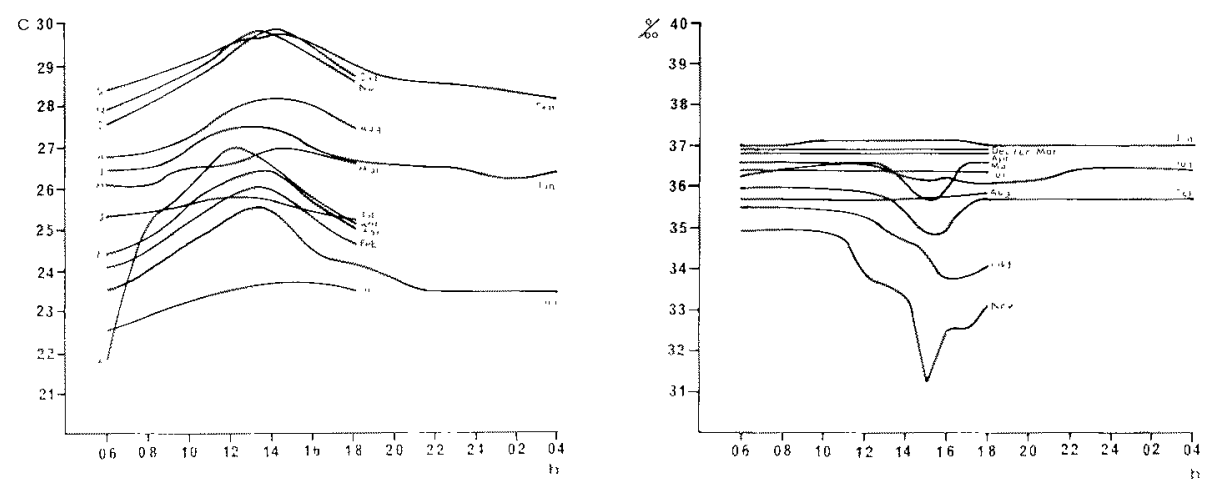

Abb. 5: (A) Tägliche Temperaturschwankungen in den einzelnen Monaten. (B) Tägliche Schwankung der Wassertemperatur in den einzelnen Monaten. Beide Messungen wurden zur gleichen Zeit und am gleichen Ort durchgeführt

Punta de Betin. Der Abfall der Kurve verdeutlicht den Zeitpunkt des Eintreffens sowie die Stärke des Einflusses des Mündungswassers vom Magdalena. Da der Wasserspiegel im Unterlauf des Magdalena während der Regenzeit ständig anstieg - das Maximum lag außethalb der Regenzeit im Dezember (KAUfmann, 1967) - wurden in den Monaten September bis November immer größere Wassermassen bis zum Meßpunkt transportiert. Dementsprechend knickte die Kurve in der Mittagszeit immer tiefer ab. Erst durch die im Dezember vorherrschende SW-Strömung wurde das Magdalenawasser wieder abgedrängt. Im April setzte sich dann vor Eintritt der kleinen Regenzeit die NO-Strömung wieder durch und führte wiederum Mündungswasser des Magdalena in die Bucht von Santa Marta.

W a s e r te m peratur. Am Ufer von Punta de Betin wurden in der Zeit von April 1971 bis April 1972 Messungen durchgeführt, die mit den Messungen der „Meteor" (aufgenommen 1927 über dem Schelf vor der Küste Kolumbiens) verglichen wurden (Abb. 3; BöHNECKE, 1936). Beide Kurven weisen ein identisches Bild auf, wobei die Kurve aus der Uferzone größere Amplituden zeigt als die Kurve der "Meteor". Außerdem ergab sich zu Beginn der großen Trockenzeit eine Phasenverschiebung, die wahrscheinlich auf die unterschiedlichen Jahresbedingungen zurüdzuführen war. Beide Kurven machten aber deutlich, daß die Temperaturen zu Beginn der Trodkenzeit stark abfielen. Eine Erklärung hierfür lag u. a. in den Windverhältnissen: Zu Beginn der "Brisazeit" trieb der ablandige Wind die Wassermassen der Oberfläche in Richtung 
offenes Meer, so daß kaltes Tiefenwasser aufsteigen konnte. Hinzu kam, daß durch den Einfluß des NO-Passates die kältere atlantische Strömung gegenüber der NO-Strömung vorherrschte. Das Niveau der einzelnen Tageskurven (Abb. $5 \mathrm{~A}$ ) entsprach der Jahreskurve. Im Durchschnitt lag das tägliche Maximum der Temperatur zwischen 12.00 und 14.00 Uhr. In der Nacht blieb die Temperatur relativ konstant.

$\mathrm{S}$ e d i m e $\mathrm{n}$ a $\mathrm{t}$ i o $\mathrm{n}$. Bei vorherrschender NO-Strömung wurden sedimentreiche Wassermassen von der Magdalenamündung bis in das Hafenbecken von Santa Maria verdriftet. Dieser Wasserkörper schob sich, dank geringerer Dichte, über das Wasser des Hafens. Beide Wasserschichten waren meistens scharf getrennt. In der „Brisazeit" brachte die SW-Strömung gelegentlich Wassermassen mit sich, die durch aufgewühlte Sedimente getrübt waren (Abb. 3). In diesem Fall nahm die Trübung mit der Tiefe zu. Bei starken Regenfällen wurde die Erde in das Wasser geschwemmt, und es sammelten sich dicke Sedimentwolken in den Uferzonen kleinerer Buchten. Derartige Sedimentationsvorgänge belasteten jedoch nur Hydroidenkolonien, die bereits einen zu starken Aufwuchs trugen.

Der Wasserkörper in der unmittelbaren Litoralregion. Die vertikale Gliederung der Wasserbewegungsarten wie Turbulenz, Schwingung und Strömung wurde von RIEDL (1964a) ausführlich besprochen, desgleichen die seitliche Versetzung des Wassers (RIEDL, 1966). An dieser Stelle soll nur verdeutlicht werden, wie die morphologische Ausgestaltung des Litorals eine Vielzahl von Sekundärbewegungen und damit unterschiedliche Mischungsverhältnisse schaff. Temperaturmessungen in der Uferregion von Punta de Betin zeigten zur gleichen Zeit in verschie-

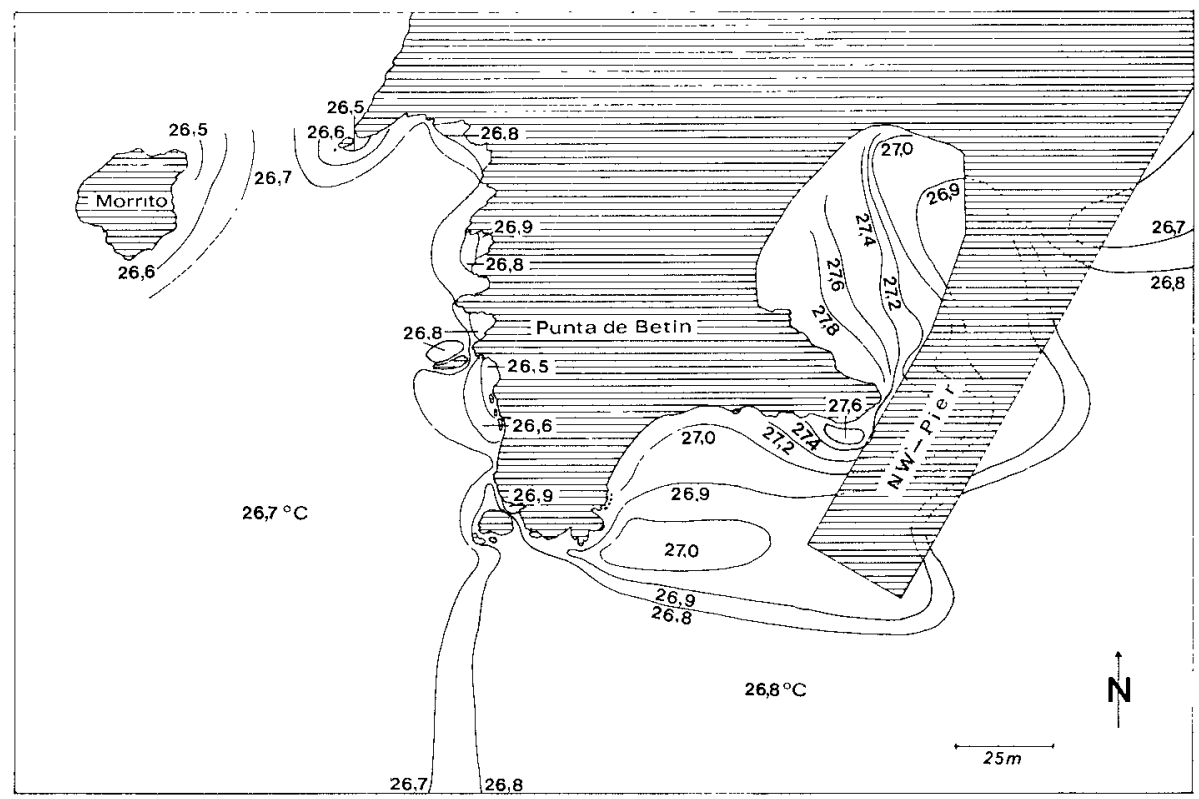

Abb. 6: Oberflächentemperatur des Wassers in der unmittelbaren Umgebung des Litorals. (Aufgenommen vor der Halbinsel Punta de Betin am 23. 3. 1972, 10.00-10.30 Uhr) 
den exponierten Regionen unterschiedliche Wassertemperaturen. Aus diesem Grund wurden ufernahe Regionen um Punta de Betin mehrmals abgefahren und dabei die Oberflächentemperaturen gemessen. Aus der Verteilung der Isothermen wird folgendes deutlich (vgl. Abb. 6): Vor Punta de Betin trafen sich zwei große Wasserkörper. Der eine kommt mit der SW-Strömung und der andere aus der Bahia de Santa Marta. An exponierten Felsklippen wurde das Wasser stark durchmischt und kühlte sich $a b$, in den Buchten erwärmte es sich. So gab es je nach Expositionsgrad hydrothermische Unter-

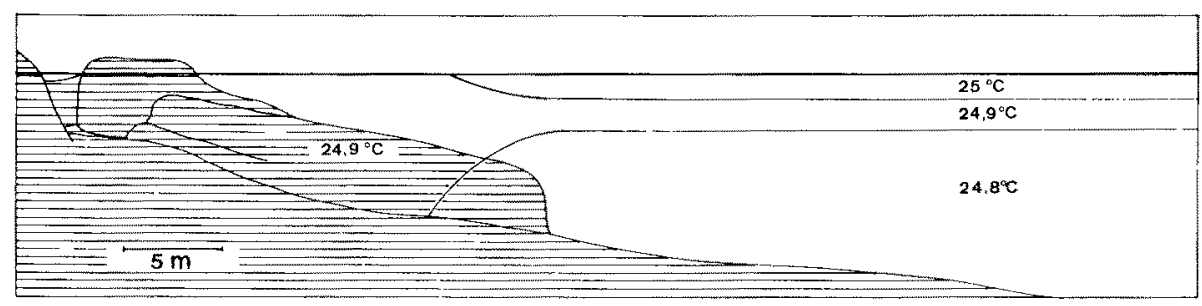

Abb. 7: Gliederung eines Wasserkörpers vor einer exponierten Felsklippc. Im Brandungsbercich wird das Wasser stark durchmischt, daher herrscht über einen relativ großen Litoralabschnitt dic gleiche Temperatur. (Aufgenommen an der Felsmauer westlich von Punta de Betin am 1. 3. 1972 um $9.00 \mathrm{Uhr})$

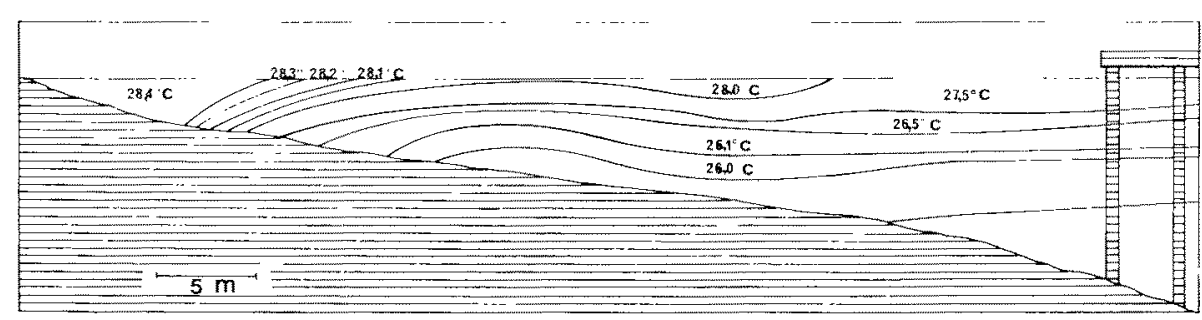

Abb. 8: Gliederung eines Wasserkörpers über einem geschützten Sandstrand. Im Wasscr sowic auf dem Benthos kann man eine sehr deutliche Temperaturabstufung erkennen. (Aufgenommen zwischen Sandstrand Punta de Betin und NW-Pier am 9. 3.1972 um 10.00 Uhr)

schiede. Die Erwärmung war am extremsten in der Ensenada de Taganquilla, wo das Wasser relativ langsam und gleichmäßig über ein Litoral mit sehr geringer Neigung und Tiefe zog. Die exponierte Klippe und die geschützte Bucht zeigten demnach jeweils unterschiedliche Temperaturbedingungen. Von jeder dieser beiden Strukturtypen wurde vor Punta de Betin eine charakteristische Region ausgesucht, in der ein vertikales Temperaturprofil ausgemessen wurde. Aus den Abbildungen 7 und 8 ist ersichtlich, daß an der Felsklippe das Wasser in der Brandungs- und Schwingungszone stark durchmischt wurde, während über dem Benthos der geschützten Bucht bis hoch zum Spülsaum das Wasser in klar abgegrenzten Temperaturschichten gegliedert war. 


\section{ƠKOLOGISCHE BEFUNDE}

\section{Untersuchungstandorte}

An folgenden Standorten wurde der wichtigste Teil der Untersuchungen durchgeführt: (1) Morrito oder Morro Chico, eine Felsinsel $100 \mathrm{~m}$ westlich von Punta de Betin (Abb. 2, Nr. 1); (2) Morro oder Morro Grande, eine Felsinsel $1 \mathrm{~km}$ westlich von Santa Marta (Abb. 2, Nr. 2); (3) Punta de Betin, eine Halbinsel vor Santa Marta: (a) Punta de Morrito, Kap zur Bahia de Taganga (Abb. 2, Nr. 3), (b) Felsmauer westlich von Punta de Betin (Abb. 2, Nr. 4), (c) Roca Druid, Felsriff SO vor Punta de Betin (Abb. 2, Nr. 5); (4) Sandstrand vor Punta de Betin (Abb. 2, Nr. 6); (5) Banco Pobea, Sandstrand vor Santa Marta (Abb. 2, Nr. 7); (6) NW-Pier, ein Kunstbau vor Punta de Betin (Abb. 2, Nr. 8); (7) Ensenada de Concha (Abb. 1, Nr. 1); (8) Punta La Loma, fossiles Riff südlich von Santa Marta (Abb. 1, Nr. 2).

\section{Standortypen}

Die nachstehende Gliederung von Standorttypen entspricht mit einigen Abweichungen der Gliederung, die RIEDL (1959) für seine Standortliste der Hydroiden des Golfes von Neapel aufstellte. Die aufgeführten Hydroidenarten wurden alle vor Santa Marta gefunden.

Treibgut. Hydroiden fanden sich auf treibendem Holz, Schilf, Sargassum, Thalassia, Zostera spec. u. a. Einige abgerissene Kolonien trieben frei an der Wasseroberfläche: Clytia colombiana, C. cylindrica, Laomedea bicuspidata, L. geniculata, Orthopyxis lennoxensis, Opercularella lacerata, Sertularia inflata, Plumularia halecoides, $P$. strictocarpa.

Phytal a f Sedimentboden. Auf Seegras (Zostera marina, Thalassia spec.) und div. Algen: Clytia colombiana, C. pelagica, C. cylindrica, Laomedea geniculata, Halecium spec., Synthecium tubithecum, Thyroscyphus ramosus, Dynamena cornicina, Sertularia inflata, Plumularia setacea, $P$. strictocarpa, P. halecoides, Monotheca margareta.

Sekundärer Hartboden auf Sediment. Als Substrate boten sich hier Schalenreste von Mollusken und Crustaceen, Holz, Samenkerne von tropischen Früchten, Korallenschutt und Schiffsabfälle an: Eudendrium carneum, Clytia spec., Halecium muricatum, Synthecium tubithecum, Cnidoscyphus marginatus, Antennella gracilis, Aglaophenia elongata.

Errantier a uf Sedimentboden. Hier unterscheiden sich Tiere, die sich auf dem Sediment bewegen (z. B. Schnecken und Crustaceen) von Tieren, die teilweise, meist bei Tag, im Sediment verschwinden (z. B. Schnecken wie Drillia spec. und Terebra taurinus): Hydractinia echinata, Clytia spec., Lovenella gracilis (auf Terebra taurinus; Abb. 10), Halopteris diaphana, Plumularia balecoides.

Sed i m e n t b od e n. Gonothyrea (?) spec., Antennella gracilis.

Phytal auf $\mathrm{Hartboden}$ der Brandungszone. Außer im Felslitoral fanden sich Algen der Brandungszone auch auf fossilen Riffen und „beach 
rocks": Halocordyle disticha, Eudendrium capillare, Clytia spec., Orthopyxis lennoxensis, Laomedea geniculata, Opercularella lacerata, Diphasia tropica, Sertularella inconstans, Dynamena cornicina, D. crisoides, D. quadridentata, Sertularia infata, Cnidoscyphus marginatus, Thyroscyphus ramosus, Halopteris diaphana, Plumularia setacea, Aglaophenia latecarinata.

Phytal auf sublitoralem Hartboden. Vereinzelter Algenwuchs auf Felsgrund: Tubularia crocea, Ectopleura dumortierii, Turritopsis nutricula, Clytia cylindrica, Laomedea bicuspidata.

$\mathrm{Sublit}$ or a ler Fels boden (stark belichtet). Felsboden mit relativ wenig Neigung, meist mit Kalkalgen und Millepora bewachsen: Clava spec., Halocordyle disticha, Syncoryne eximia, Halecium bermudense, Dynamena cornicina.

Sublitoraler Felsboden (Halbschatten). Standort mit wechselnder Belichtung. Algenwuchs meist nur epiphytisch vorhanden: Garveia bumilis, Halocordyle disticha, Corydendrium parasiticum, Ectopleura dumorierii, Tubularia crocea, Eudendrium carneum, E. ramosum, Laomedea dichotoma, L. geniculata, L. tottoni, Halecium bermudense, Sertularella speciosa, Dynamena cornicina, D. crisoides, Cnidoscyphus marginatus, Thyroscyphus ramosus, Halopteris diaphana, H. carinata, Cladocarpus (?) spec., Plumularia megalocephala, P. setacea, Lytocarpus philippinus, Gymnagium speciosum.

Sublitoraler Felsboden (tiefer Schatten). Kein direktes Licht. Nur noch epiphytische Rotalgen. Felsen mit starkem Aufwuchs: Corydendrium parasiticum, Eudendrium carneum, Cridloscypbus marginatus, Sertularella speciosa, Sertulatia inflata, S. turbinata, Halopteris carinata.

Sublitoraler Felsboden (nahezu lichtlos). Diese Zone findet man nur in Höhlen, die so tief sind, $\mathrm{d} a ß$ in Innern völlige Dunkelheit herrscht. Hier keine Hydroiden.

Sedentarier im Fels litoral. (a) Auf Schwämmen: Tubularia crocea, Halocordyle disticha, Halecium bermudense, Laomedea tottoni, Plumularia halecoides, Halopteris carinata. (b) Auf Hydroiden: Clawa spec, Garreia humilis, Clytia pelagica, C. spec, Laomedea geniculata, L. tottoni, L. bicuspidata, L. dichotoma, Hebella patrasitica, Cuspidellat bumilis, Sertularella inconstans, S. turbinata. (c) Auf Gorgonien: Halocordyle disticha, Laomedea dichotoma, Dynamena cornicina, Cnidoscyphus marginatus, Sertulerella speciosa, Halopteris carinata. (d) Auf Tunicaten: Laomedea geniculata, Dynamena crisoides, Sertularia turbinata, Plumularia setacea. (e) Auf Balaniden: Sertularella spec., Dynamena comicina, D. crisoides, Plumularia setacea.

Errantier im Felslitoral. Hydroiden saßen vor allem auf Schnecken (z. B. Citharium pica) oder wurden von Crustaceen, die zwischen Hydroidenkolonien lebten, zur Tarnung auf den Panzer gesteckt: Eudendrinm carneum, Dynamena crisoides, Cnidoscyphus marginatus.

Ku n t b a t e n (b e w e g lich). Hierunter fallen Schiffs- und Bootsrümpfe und Bojen. Da diese Körper schwimmen, macht sich bei ihnen, im Gegensatz zu den festen Kunstbauten, der Gezeitenhub nicht bemerkbar: Halocordyle disticha, Eudendrium spec, Laomedea dichotoma, Halecium bermudense, Cnidoscyphus marginatus, Sertularia turbinata, Plumularia setacea.

K u n stba u te n ( $f$ est). Bootsstege, Hafenanlagen, Betonsäulen u. a.: Halo- 
cordyle disticha, Bougainvilla ramosa, Coridendrium parasiticum, Clava spec., Tubularia crocea, Ectopleura dumortierii, Eudendrium carneum, Laomedea congdoni, $L$. tottoni, $L$. bicuspidata, $L$. dichotoma, $L$. spec., Halecium bermudense, $H$. spec., $H$. tenellum (?), Idiella pristis, Diphasia digitalis, Dynamena crisoides, Cnidoscyphus marginatus, Sertularella speciosa, S. inconstans, Sertularia turbinata, Cladocarpus (?) spec., Lytocarpus pbilippinus, Antennella gracilis.

\section{B esied 1 ung}

\section{Stoloniale Besiedlung}

Im Litoral von Santa Marta konnte bei Cnidoscyphus marginatus, Sertularia inflata, Halopteris diaphana, Plumularia setacea und Aglaopbenia latecarinata beobachtet werden, wie diese Arten mittels Ausläufer einen neuen, vom eigenen Biotop räumlich. getrennten Lebensraum eroberten. Dies geschah an Standorten, wo durch rhythmische Wasserbewegung Teile der Kolonie mit einem Nachbarsubstrat in Berührung kamen, also im Phytal und an dichtstehenden Betonsäulen. Durch den ständigen Bewegungsreiz bildeten sich Stolonen, die in einem günstigen Moment am Nachbarsubstrat festhefteten und bei einer Gegenbewegung des Wasserkörpers abrissen.

Einen gleichartigen Vorgang beobachtete TARDENT (1965) bei Aglaophenia spec. auf Posidonia oceania.

\section{Besiedlung durch Frusteln}

Frustelbildungen sowie die anschließende Besiedlung wurden bei Laomedea bicuspidata im Labor beobachtet. Durch Klimaverschlechterung bildeten sich an den Spitzen der Kolonien Ausläufer, in denen sich Frusteln abschnürten. Diese krochen durch die Kulturschale und besiedelten die angebotenen Nylonschnüre (nicht die Glaswände). Anschließend bildeten sich wieder neue Polypen aus.

\section{Besiedlungsfolge}

Die Frequenz der Besiedlung war von Art zu Art verschieden. Kurzlebige Arten verbreiteten sich jedoch prinzipiell häufiger als langlebige Arten. Diese Tatsache sowie die verschiedenen Reifezeiten der einzelnen Populationen regelte die Besiedlungsfolge innerhalb einer Biozönose.

Besiedlungsfolge und -frequenz sessiler mariner Tiere wurden von COE (1932) eingehend über einen längeren Zeitraum beobachtet. Leider berichtete er wenig über die Besiedlung durch Hydroiden. Er stellte nur fest, daß Laomedea dichotoma einer der ersten Siedler war und von Plumularia setacea gefolgt wurde.

Unter der NW-Pier wurden an geschützten Stellen Platten ausgelegt. Die ersten Siedler waren auch hier, neben den Polychäten Eupomatus gracilis und Serpula columbiana, Kolonien von Laomedea dichotoma. Es folgten im hiesigen Falle Laome- 
Hydroiden des Felslitorals

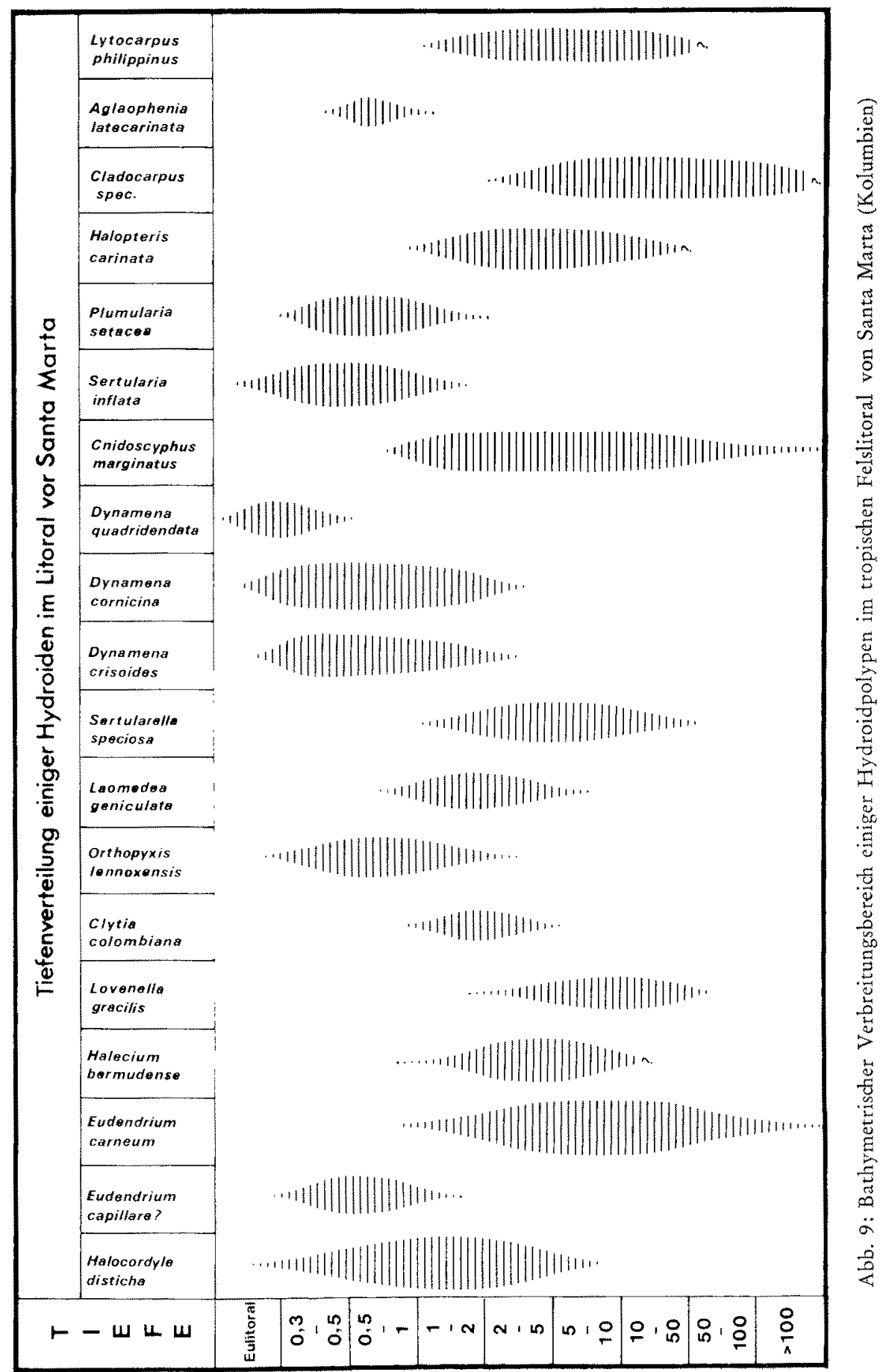


dea tottoni und Sertularia turbinata. Dann breiteten sich krustige Bryozoen aus, die später von Cnidoscypbus marginatus überwuchert wurden. Nun folgten Balaniden (vor allem Balanus tintinnabulum) und der Hydroidpolyp Sertularella inconstans.

Der weitere Siedlungsablauf wurde an Hand von Schnittproben durch den vorhandenen Aufwuchs rekonstruiert. Danach folgten zuerst Tunikaten und anschließend Muscheln. Während der ganzen Zeit wurden Substrat und Aufwuchs von Schwämmen besiedelt, die aber entweder verdrängt wurden oder sich ebenso wie die Hydroiden immer wieder neuen Raumverhältnissen anpassen mußten. Die Endstufe in der Besiedlung bildeten Hydroiden, wie Eudendrium carneum, Idiella pristis, Dipbasia digitalis, Cnidoscyphus marginatus, Sertularella speciosa und andere Arten. Das Grundschema der Besiedlungsfolge (kurzlebige, ökologisch dynamische Formen vor längerlebenden, ökologisch statischen Formen) dürfte überall gleich sein.

Längere Beobachtungen zeigten, daß der Aufwuchs am Kunstbau und im Felslitoral sowie seine Zonierung in dieser Tropenregion im großen und ganzen quantitativ und qualitativ konstant blieb. Besiedlungsmöglichkeiten, die auch sofort ausgenutzt wurden, ergaben sich meist nur, wenn auf Grund von Erosionen oder durch Abweiden Substratflächen frei wurden. Weitere Substrate entstanden durch neue Kunstbauten und feste Abfallprodukte.

\section{Wabl des Besiedlungsortes}

Man kann drei Möglichkeiten für eine Besiedlung unterscheiden: (1) Die ausgeschwärmten Planulae besiedeln direkt einen für den Aufwuchs günstigen Standort: Besiedlungsort $=$ Aufwuchsort. (2) Die Planulae verteilen sich zufällig. Diejenigen,

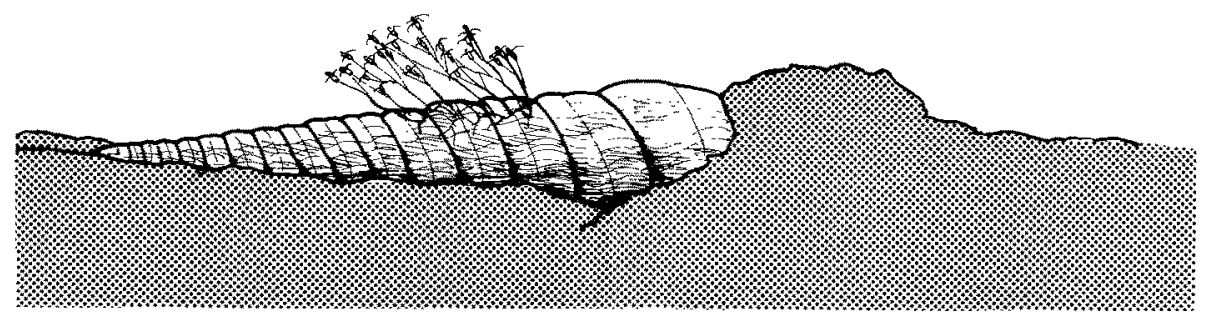

a

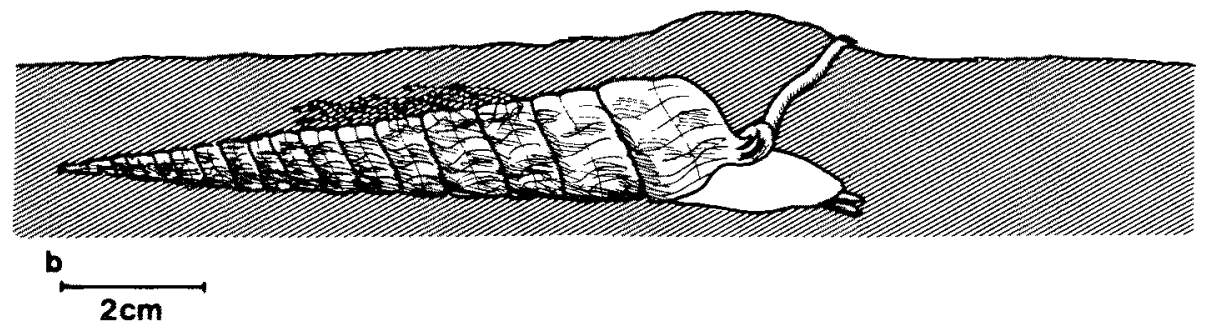

Abb. 10: Lovenella gracilis auf Terebra taurinus. (a) Bei Nacht bewegt sich die Schnecke auf der Sedimentoberfläche, und die Hydroiden entfalten sich. (b) Bei Tag verschwindet die Schnecke im Sediment. Die Theken der Hydroiden sind durch Opercula verschlossen 


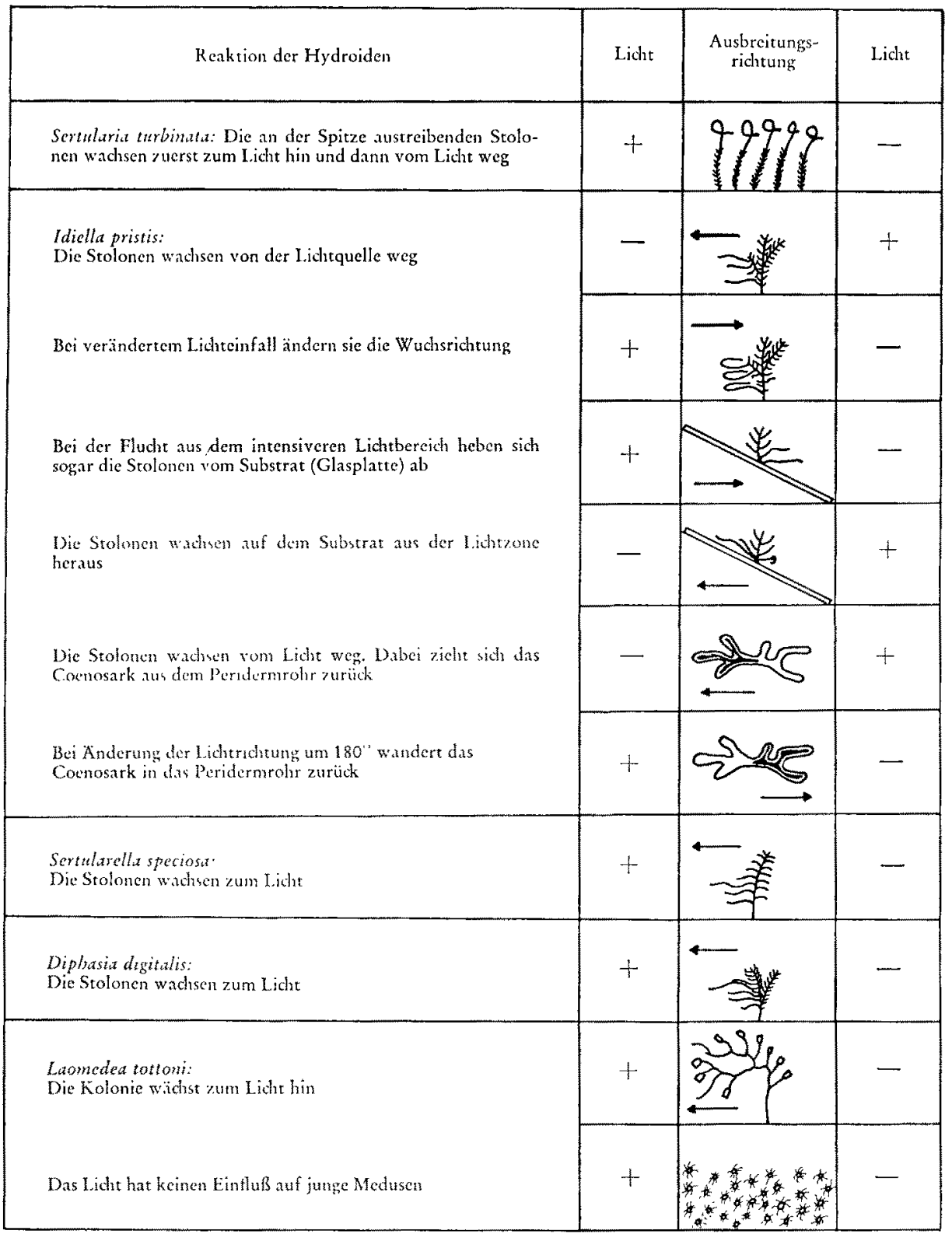

Abb. 11: Einfluß des Lichtes auf die Ausbreitung von Hydroidenkolonien (dargestellt anhand einiger Laborversuche). $+=$ hell, $\ldots$ dunkel 
welche die günstigsten Bedingungen erreichen, bilden Polypen aus. (3) Die Planulae verteilen sich zufällig. Sie können aber, falls sie ein für den Aufwuchs ungünstiges Substrat besiedeln, den Standort wechseln, d. h. ihren Aufwuchsort selbst auswählen: Besiedlungsort $\neq$ Aufwuchsort.

Der Fall Nr. 1 würde voraussetzen, daß die Planula fähig ist, einen bestimmten Platz schwimmend zu erreichen. Sie ist aber nicht in der Lage, sich gegen eine etwas stärkere Wasserbewegung durchzusetzen. Sie kann aber, wie es folgende Beobachtung zeigt, in kleinen Grenzen ihre Verdriftung auf ein bestimmtes bathymetrisches Niveau einengen bzw. selbst eingeengt werden. Am 20.7.1971 wurde eine Säulenreihe der NW-Pier in einer für diese Art charakteristischen Tiefe von 1,5-3 m durch Planulae von Laomedea tottoni besiedelt. Bereits nach zwei Tagen waren in diesem Bereich große Koloniebestände ausgebildet. $\mathrm{Da}$ die Säulen untereinander nicht verbunden waren, konnten sie nur durch eine größere Anzahl gemeinsam driftender Planulalarven besiedelt worden sein.

Aus Gründen der Wahrscheinlichkeit kann Fall 2 bei allen Hydroidenarten zutreffen.

Fall Nr. 3 trift zu, wenn: (a) die Planula ihre ungünstige Umgebung als solche erkennt, (b) wenn sie darauf reagiert, d. h. den Ort wechselt.

Eigene Beobachtungen im Labor und die von Müller-Cale \& KRÜGer (1913) sowie Williams (1965) zeigten, daß Planulae von Hydroiden, die in extremen Verhält-

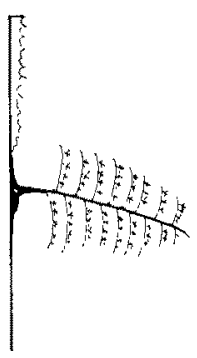

a

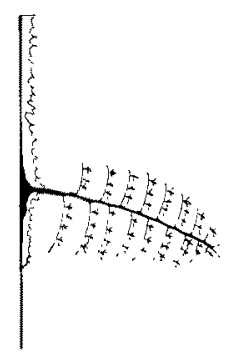

b

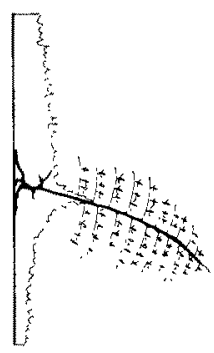

c

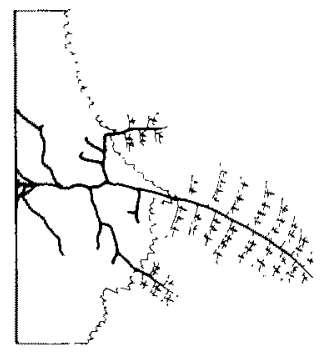

d

Abb. 12: Der Hydroidpolyp Halocordyle disticha auf einem Schwamm (d). Die Phasen a-d zeigen, daß der Schwamm den Hydroidpolyp besiedelt und nicht, wie das Endstadium (d) vermuten läßt, der Hydroidpolyp den Schwamm

nissen wie z. B. in der Brandungszone leben (so z. B. Clava squamata, Sertulariden, Aglaopheniden u. a.), sich über Schwerkraft, Lichtintensität, durch Chemotaxis und Thigmotaxis orientieren können. LoEB (1914) stellte fest, daß sich Eudendrium im Wuchs stark nach dem Licht orientiert.

Eigene Versuche zeigten, daß sich Planulae von Eudendrium carneum in einer Lichtorgel bestimmte Helligkeitszonen aussuchten, um dort in Gruppen angeordnet Polypen auszubilden. Weiterhin wurden Hydroidenkolonien verschiedener Arten qualitativ und quantitativ unterschiedlichem Licht ausgesetzt. Die Ergebnisse einiger dieser Versuche zeigt Abbildung 11. Versuche in unterschiedlichen Spektralbereichen ergaben, 
daß bei den meisten Arten die langwelligen Lichtstrahlen weniger wahrgenommen werden als die kurzwelligen.

\section{Substrate}

Bevorzugte Substrate der Hydroiden waren exponierte Standorte, vor allem exponierter Aufwuchs, wie Algen (besonders im Brandungsbereich, vgl. KATO, 1961), Seegras (auf Sandlitoral), Hydroiden, Muscheln, Tunikaten und besonders Schwämme (im Felslitoral) (vgl. Tab. 1).

Schwämme wurden entweder durch freischwimmende Planulae besiedelt, wobei sich hier die Kolonien der Hydroiden meist um die Poren aufbauten. Abbildung 12 verdeutlicht aber, daß auch Hydroiden von Schwämmen besiedelt wurden, wie durch längere Beobachtungen festzustellen war.

In der Umgebung von Santa Marta wurden folgende Hydroidenarten auf Schwämmen gefunden: Halocordyle disticha, Tubularia crocea, Halecium bermudense, Laomedea tottoni, Halopteris carinata, Plumularia balecoides und P. megalocephala. Kleine Kolonien von Halecium bermudense (1-4 cm) wurden zu etwa $90 \%$ nur auf Schwämmen angetroffen, dagegen niemals große und reife Kolonien.

\section{Ausbreitung der Bestände}

Der Ausbreitungstendenz eines Bestandes wurden von authen her durch abiotische und biotische Faktoren Grenzen gesetzt, d. h. das autökologische Potential der jeweiligren Arten kam im synökologischen Gefüge nur soweit zur Geltung, wie es die gegebenen Lebensbedingungen zuließen. Der Bestand wurde dadurch auf einen bestimmten Verbreitungsbereich eingeengt. Tabelle 2 veranschaulicht den Verbreitungsspielraum einiger Hydroidenarten vor Santa Marta in unterschiedlichen Bewegungsbereichen.

Die Gattungen Plumularia und Aglaophenia waren an cinen relativ engen Bewegungsbereich gebunden. Andererseits lebten z. B. Halocordyle, Eudendrium und Cnidoscyphus unter recht unterschiedlichen Bewegungsbedingungen.

In Freilandexperimenten wurden mehrere an eine bestimmte Wasserbewegung gewöhnte Hydroiden in ein zum eigenen Biotop konträres Milieu verpflanzt. So wurden z. B. aus dem Brandungsbereich Sertularia inflata und Plumularia setacea in eine gemäßigte Strömung unter einem Kunstbau und aus eben dieser Umgebung Eudendrium carneum, Cnidoscyphus marginatus und Sertularella speciosa in den extremen Brandungsbereich versetzt. Dabei zeigte sich, daß die $\mathrm{H}_{y}$ droiden aus der stärker bewegten Region in der ruhigen Umgebung ausgezeichnet wuchsen. Sie wurden jedoch bald von schnellwachsenden Sedentariern, in der Mehrzahl Kleinhydroiden, überwuchert und erstickt. In die Brandungszone umgesetzte Hydroiden wurden dagegen rasch von den ungewohnt starken hydrodynamischen Kräften zerstört und erholten sich nicht mehr.

All diese Umsiedlungsversuche ließen deutlich erkennen, daß Hydroiden aus einem ökologisch relativ begrenzten Lebensraum auch in einem wesentlich größeren graduellen Spielraum existieren könnten, auch wenn sie in Wuchsform und Lebensweise schein- 
Tabelle 1

Beziehungen zahlreicher Hydroiden zum Substrat $(\bullet=$ bevorzugtes Auftreten, $\circ=$ selteneres Auftreten)

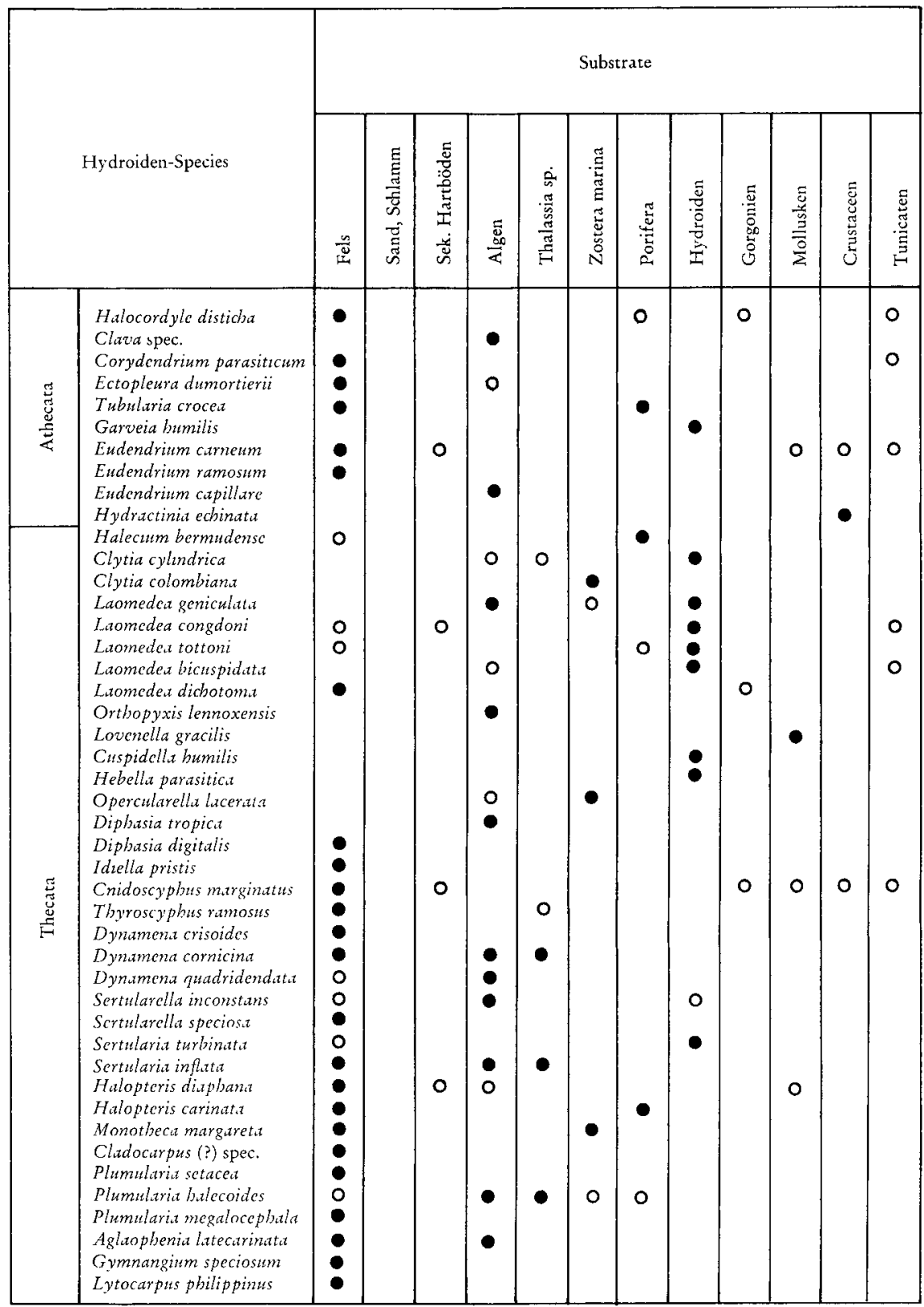


bar an einen bestimmten Verbreitungsbereich gebunden waren. Andere ökologische Faktoren engten aber die Entfaltungsmöglichkeiten wieder ein.

Tabelle 3 veranschaulicht den Verbreitungsbereich einiger Hydroiden vor Santa Marta in verschiedenen Lichtzonen. Dabei ist zu beachten, daß die Helligkeitsabstufungen in den einzelnen Litoralabschnitten (besonders im Felslitoral) räumlich und zeitlich sehr stark schwankten. Aus diesem Grunde ließen sich den einzelnen Faunenbeständen

Tabelle 2

Beziehungen einiger Hydroiden zur Wasserbewegung

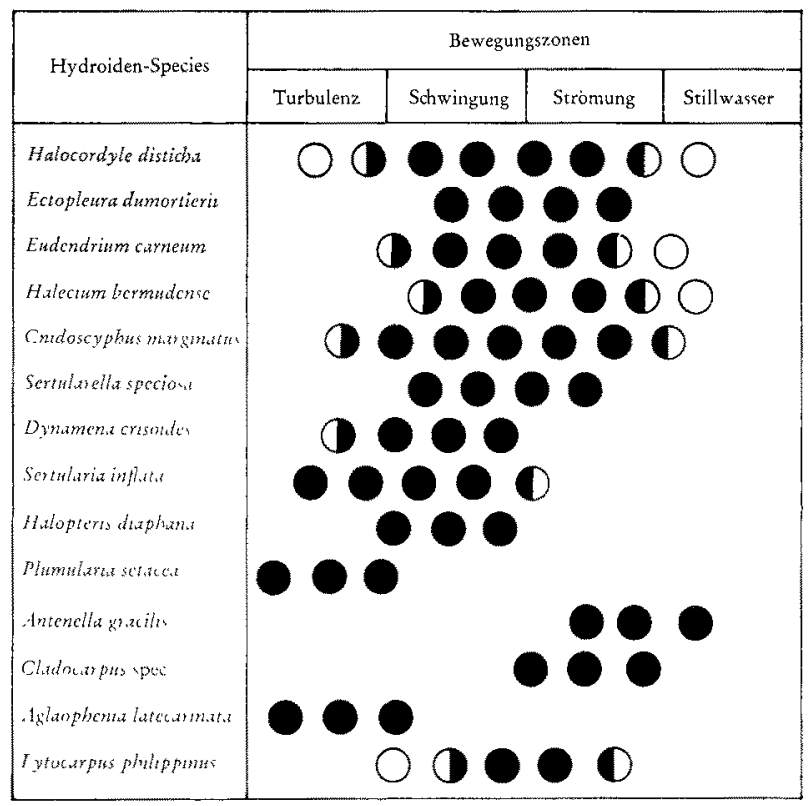

(Zonen) bestimmte Helligkeitswerte immer nur bedingt zuordnen. Abbildung 13 verdeutlicht den Spielraum einiger Hydroiden in unterschiedlichen Licht- und Bewegungsbedingungen.

Um festzustellen, ob sich eine graduelle Abstufung der Lichtverhältnisse direkt oder indirekt über ihre Folgeerscheinungen (z. B. Algenwuchs) auf die Gestaltung einer Biozönose und Abgrenzung eines Biotopes auswirkte, wurden verschiedene Hydroidenpopulationen daraufhin beobachtet. Dabei wurden Bestände ausgewählt, die sich möglichst nur in dem zu messenden Faktor Licht von den zu vergleichenden Populationen oder Standorten unterschieden. Folgende drei Bestände sollen hier besonders betrachtet werden: (a) Sertularia inflata in einer Blockhöhle vor Punta de Betin. Die Höhle war an zwei Seiten offen. An beiden Offnungen bestand ein deutliches Lichtgefälle. (b) Dynamena crisoides im Felslitoral der Südflanke der Bucht Ensenada de Concha. Die Morphologie der Uferlandschaft sowie der Verlauf der täglichen Sonnenbahn waren die Ursachen für das kryptophile und akrophile Auftreten in unmittelbarer Nachbar- 
Tabelle 3

Verbreitung einiger Hydroiden in verschiedenen Lidhtzonen

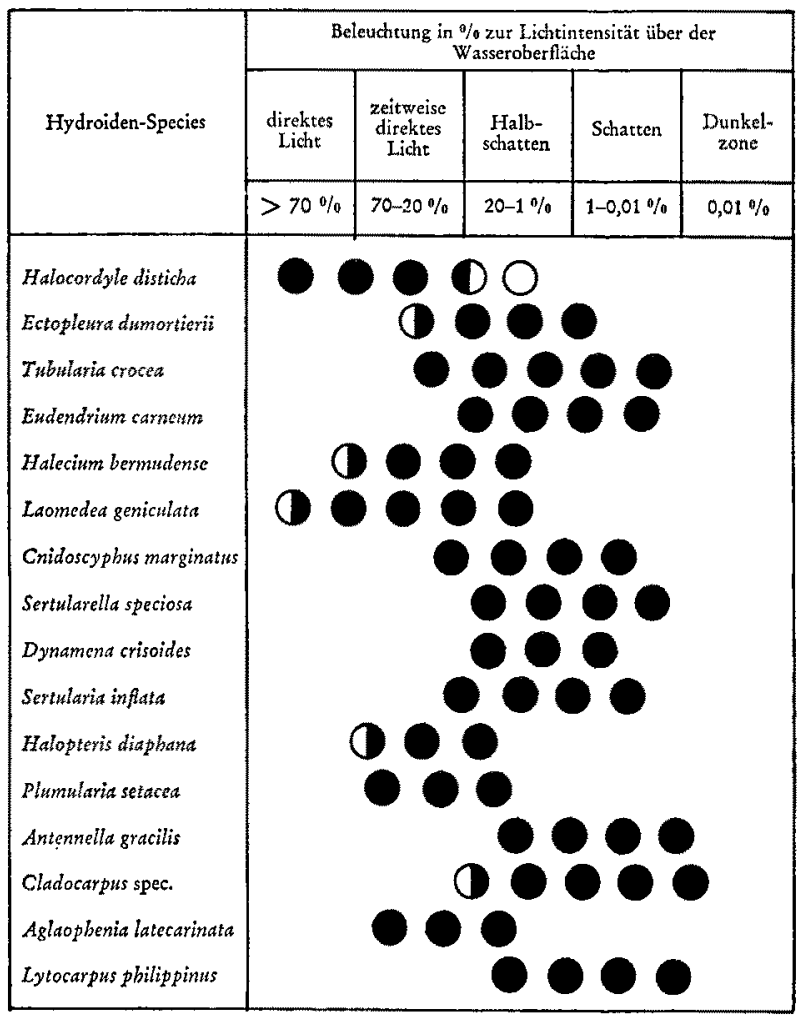

schaft. (c) Eudendrium carneum an den Säulen des Bootshauses der Ensenada de Taganquilla. Die Verteilung der Art wurde beeinflußt durch den relativen Verlauf der täglichen Sonnenbahn.

\section{Blockböhle mit Sertularia inflata}

Der zu untersuchende Sertularia-Biotop (Abb. 14) zeigte die gleiche Wasserbewegung, Wassertemperatur, Substratneigung $u$. a. wie die von dieser Art nicht besiedelte Umgebung. Seewärts der Blockhöhle war das Substrat ebenfalls frei von dieser Hydroidenart, uferwärts dagegen waren einige Steine an ihren Schattenstellen besiedelt. Eine Abstufung der Beleuchtungsintensität lag nur in den Höhlenöffnungen vor. Daher genügte es, einen Schnitt durch die Längsachse der Höhle zu legen. Da Sertularia inflata eindeutig die Schattenregion dieses Litoralabschnittes besiedelte und außerdem das ganze Jahr über in gleicher Dichte anzutreffen war, ließ sich die Abundanz der Population mit dem Gefälle der Lichtintensität in Relation setzen (Abb. 15). 
Der innere Abschnitt (Felder 6-13) erhielt den ganzen Tag über kein direktes Licht (nur Streulicht). Die Hydroiden dieses Abschnittes waren in Maximalgröße und frei von Algen. Die Felder 4, 5 und 14 bekamen zeitweise direktes Licht. Hier waren die Hydroiden klein und veralgt und nahmen in ihrer Dichte nach außen hin ab. Außerhalb der Meßfelder sowie auf den Feldern 1-3 trat $S$. inflata nicht mehr auf. Aus dem Blockdiagramm (Abb. 16 B) ist ersichtlich, daß die algenfreien Hydroiden alle

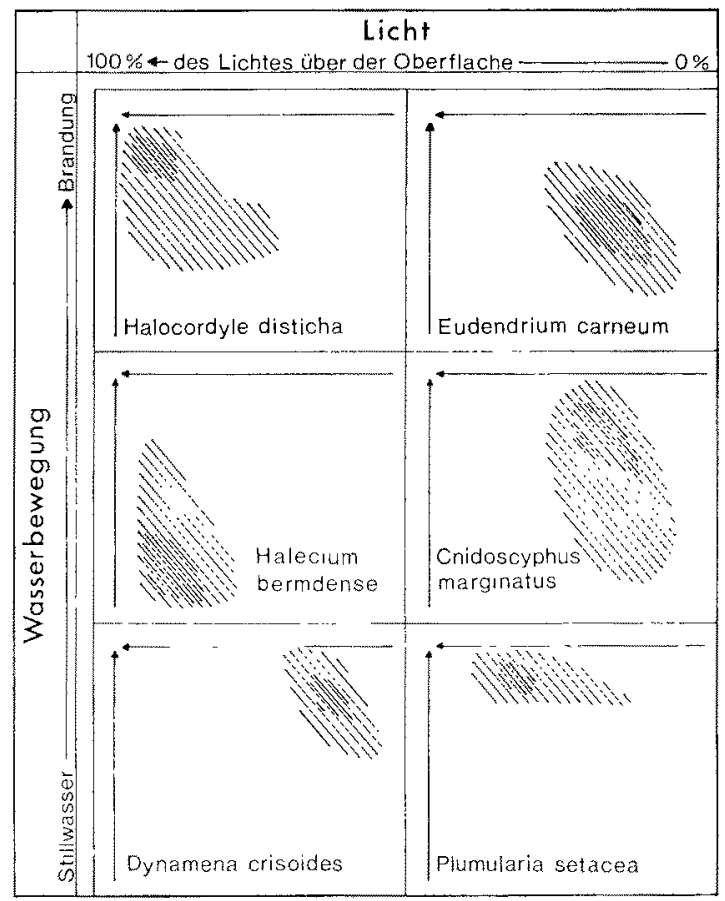

Abb. 13: Diagramm der Beziehungen zwischen Licht und Wasserbewegung bei einigen Hydroiden. Die schraffierte Fläche veranschaulicht den Verbreitungsbereich. Die eng schraffierte Fläche gibt den Bereich für das bevorzugte Auftreten an

etwa gleich groß waren. Die Abundanz nahm jedoch nach innen etwas zu (Abb. $16 \mathrm{~A}$, $22 \mathrm{~A}$ ). Bemerkenswert war der deutliche Abfall in der Abundanz von den unveralgten zu den veralgten Hydroiden.

Die äußeren Verhältnisse in diesem bewegten Litoralabschnitt waren optimal für die Existenz von $S$. inflata. Diese Art konnte jedoch nur dann existieren, wenn die Konkurrenz der Algen, die in dieser Tiefe (etwa $1 \mathrm{~m}$ ) sonst sehr stark auftraten, infolge Lichtmangels zurückgedrängt wurde. Daher war S. inflata im Felslitoral immer nur unter Steinen, in deren Schatten oder im Phytalschatten zu finden.

Bei einer durchschnittlichen Lichtintensität von unter $20 \%$ bis etwa $2 \%$ des vollen Tageslichtes stand diese Art im Existenzkampf mit den Algen. Unter $2 \%$ bestand dagegen keine Algenkonkurrenz mehr. 


\section{Akropbilie und Kryptophilie bei Dynamena crisoides}

Dynamena crisoides wuchs im Felslitoral der Umgebung von Santa Marta in Halbschattengebieten des oberen Sublitorals. Bevorzugte Standorte waren die Unterseiten von Felsüberhängen und die äußeren Regionen von Höhlendächern. Außerdem fanden sich Kolonien an den oberen Pfeilerabschnitten der NW-Pier in den vorderen Streulichtzonen. Die Art lebte also bevorzugt verborgen - kryptophil - unter einem "Dach“.

Am Südende der Ensenada de Concha fand sich jedoch eine Stelle, an der die Art wie gewohnt unter Überhängen sowie auch exponiert - akrophil - auftrat. Beide Ex-

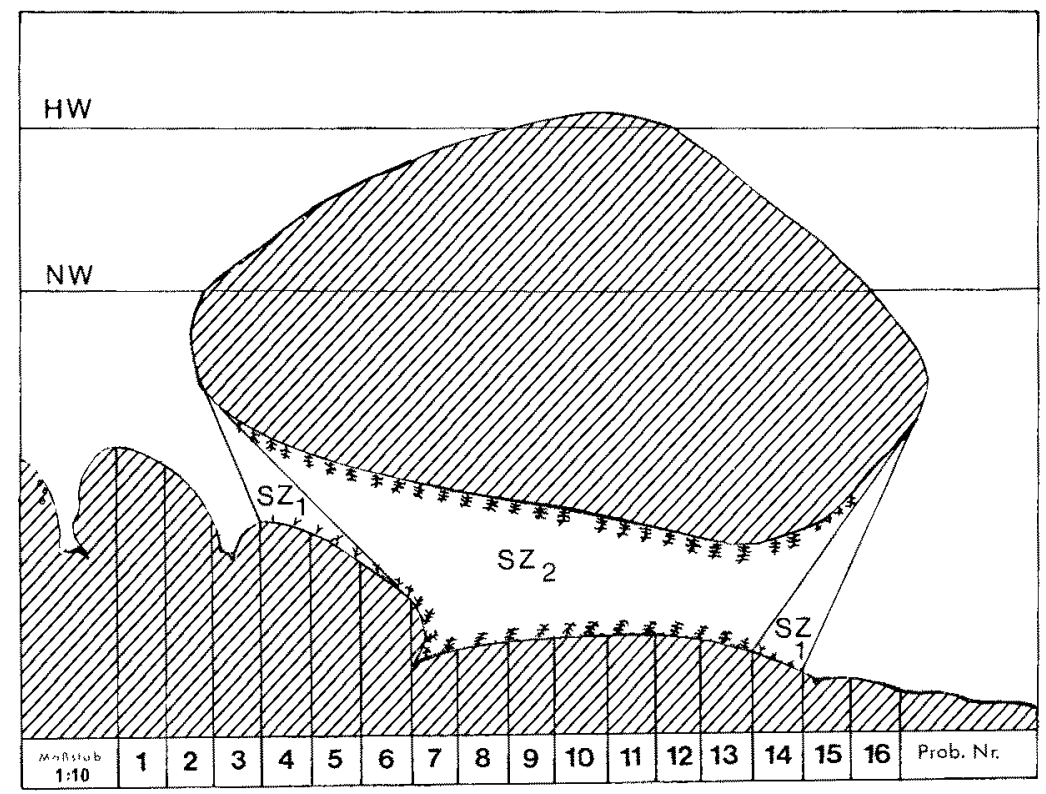

Abb. 14: Schnittbild durch eine Blockhöhle im Brandungsbereich westlich von Punta de Betin. Die Wände der Höhle sind innen vollkommen mit Kolonien von Sertularia inflata überzogen. $\left(\mathrm{HW}=\right.$ Hochwasserlinie, $\mathrm{NW}=$ Niedrigwasserlinie, $S \mathrm{Z}_{1}=$ Streulichtzone 1 mit zeitweise direktem Sonnenlicht, $\mathrm{SZ}_{2}=$ Streulichtzone 2 ohne direktem Sonnenlicht, Probenummern 1-16 = Nummer der Registrier- bzw. Meßfelder)

positionsformen lebten hier in gleicher Tiefe und bei gleichartiger und gleichstarker Wasserbewegung dicht nebeneinander. Das hier kräftig bewegte Wasser wurde sehr stark durchmischt. Daher waren Temperatur, Sauerstoff, Chemismus und andere Faktoren in beiden Fällen gleich. Beobachtungen der Populationen über einen längeren Zeitraum hinweg ergaben, daß die einzelnen Standorte unterschiedlich stark und lange beschattet waren (Abb. 17). Der Grund hierfür lag in der Morphologie der Uferlandschaft.

An vier charakteristischen Stellen (Meßplätze 1-4) wurden die Lichtwerte eines ganzen Tages gemessen (vergl. Abb. 18): (1) Die Hydroiden standen exponiert; Helligkeitsmaximum 16.00 Uhr. (2) Die Hydroiden standen exponiert; Helligkeitsmaximum 


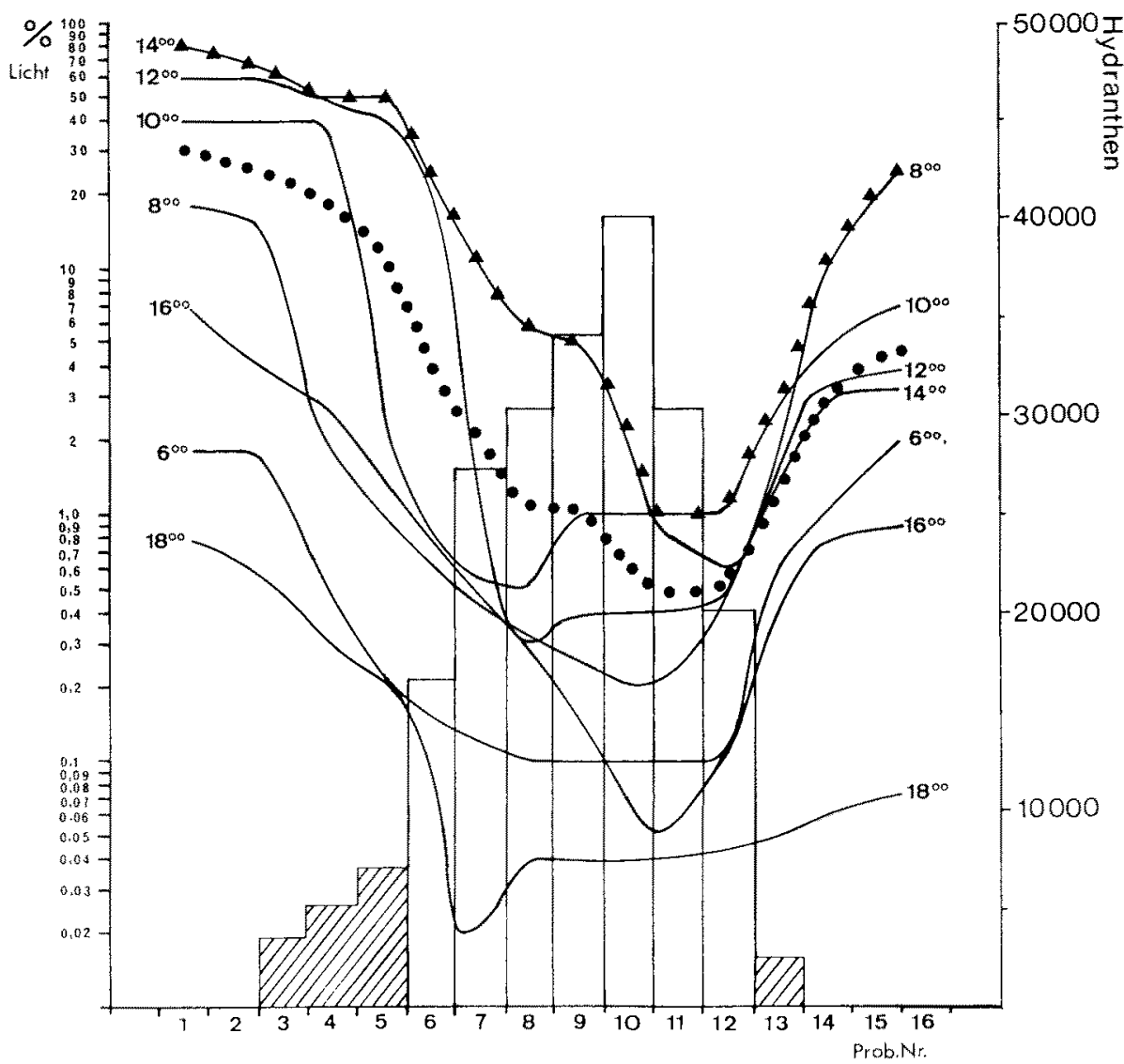

Abb. 15: Wechselbeziehung zwischen täglichem Lichteinfall und Wuchsdichte cincr Sertularia inflata-Population in einer Blockhöhle. (Schrafferte Balken = veralgte Hydroidenkolonien; weiße Balken $=$ unveralgte Hydroidenkolonien; Punkt-Linie $=$ Lichtmenge im Tagesdurchschnitt; Dreieck-Linie $=$ maximale Beleuchtung pro Tag. Die Lidhtmenge wurde in $\%$ zum maximalen Lichteinfall auf die Wasseroberflïche gemessen)

A

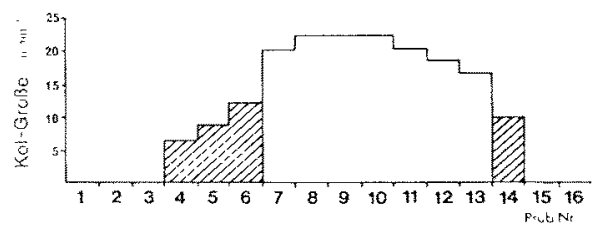

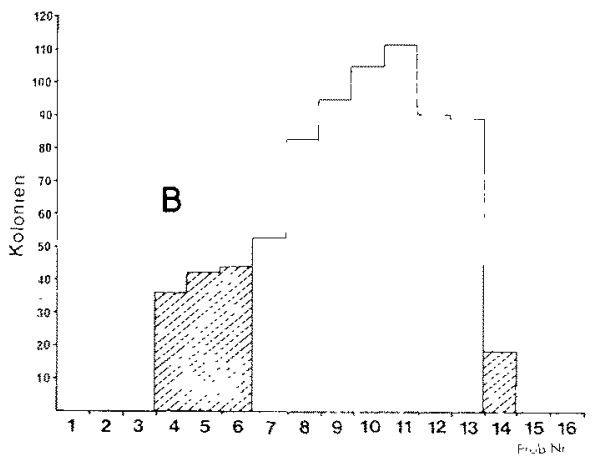

Abb. 16: (A) Länge der Polypenstöckchen in den Meßfeldern der Höhlenlïngsachse. (B) Anzahl der Kolonien in den Meßfeldern der Höhlenlängsachse 

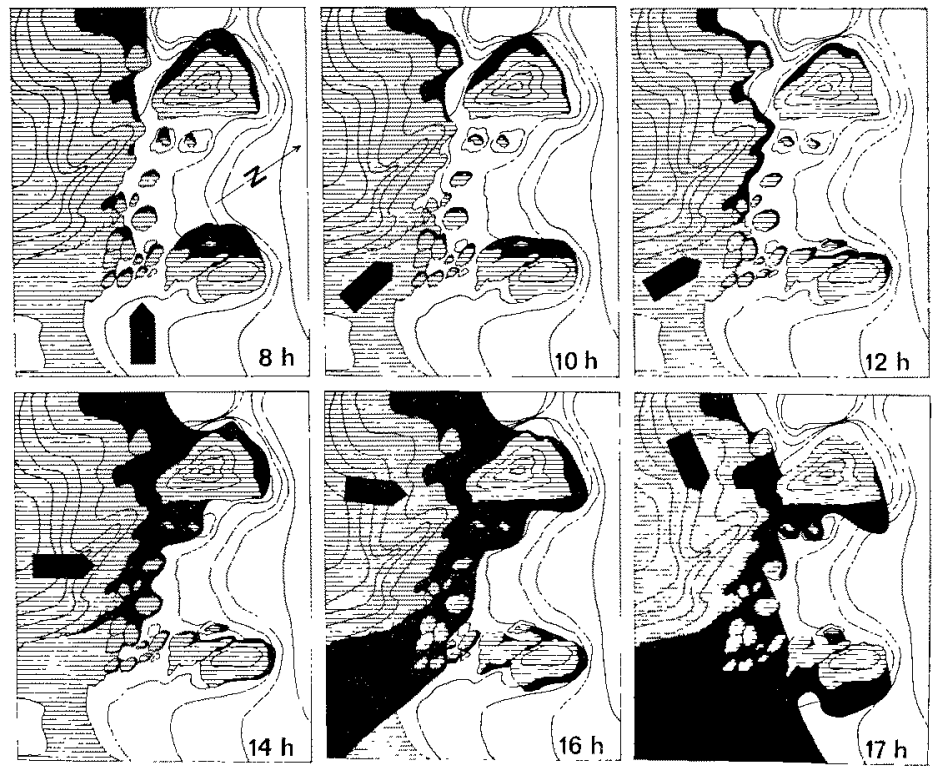

Abb. 17: Wechselnde Beschattung einer Felslitoralregion im Laufe eines Tages. Der schwarze Pfeil gibt die Einfallsrichtung der Sonnenstrahlen an. (Das Schattenbild wurde am Südende der Ensenada de Concha aufgenommen)

10.00 Uhr. (3) Keine Hydroiden, aber Litoralverhältnisse wie bei den Meßplätzen 1 und 2. Der Meßplatz lag aber den ganzen Tag über im Sonnenlicht. (4) Die Hydroiden wuchsen unter einem Felsüberhang, ein typischer Standort für Dynamena crisoides. Da man die gemessenen Skalenteile proportional der Lichtenergie setzen konnte, war deutlich zu sehen, daß der Meßplatz 3 mit wesentlich mehr täglicher Sonnenenergie versorgt wurde als die übrigen Meßplätze. Die Standorte 1 und 2 erhielten etwa die gleiche Menge an Lichtenergie wie der Standort 4. Die Lichtmenge reichte also hier noch nicht aus, um den epiphytischen Algen zu einem Ưberdruck zu verhelfen.

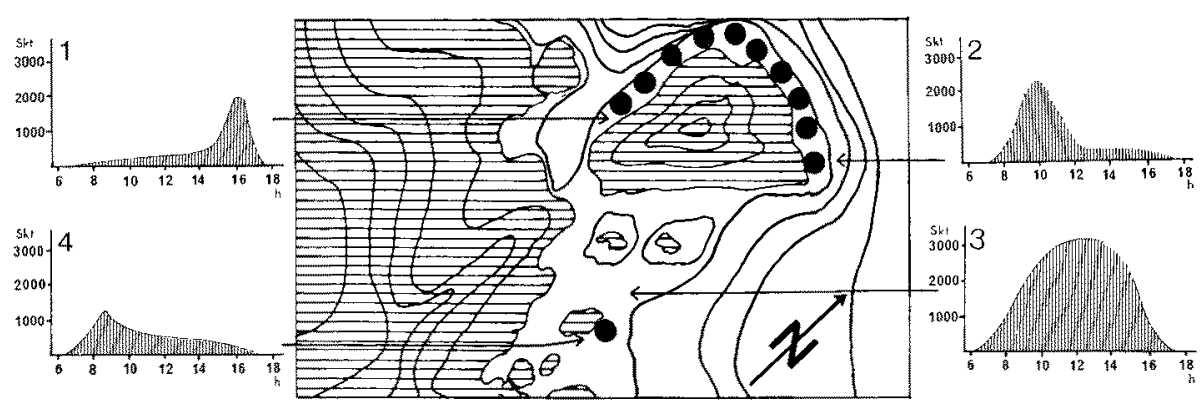

Abb. 18: Standorte von Dynamena crisoides (schwarze Punkte) in Regionen mit unterschiedlicher Beleuchtungsperiode. Meßstellen 1 und 2: Die Hydroiden stehen exponiert; Meßstelle 3: Bis auf die Beleuchtung absolut gleiche Standortbedingungen wie in 1 und 2, aber kein Hydroidenbewuchs; Meßstelle 4: Die Hydroiden leben hier in ihrer normalen Expositionsstellung (unter einem Höhlendach) 


\section{Bootssteg mit Eudendrium carneum und Halocordyle disticha}

An den Säulen des Bootssteges und des alten Bootshauses in der Ensenada de Taganquilla wuchsen zur Untersuchungszeit große Bestände von Eudendrium carneum und Halocordyle disticha. Auffallend war, daß die Eudendrium-Kolonien auf der NW-Seite der Pfeiler wuchsen und nur den mittleren bis hinteren Bereich der Pfeilergruppe besiedelten. Die vorderen Säulenreihen wurden, meist rundum, von Halocor-

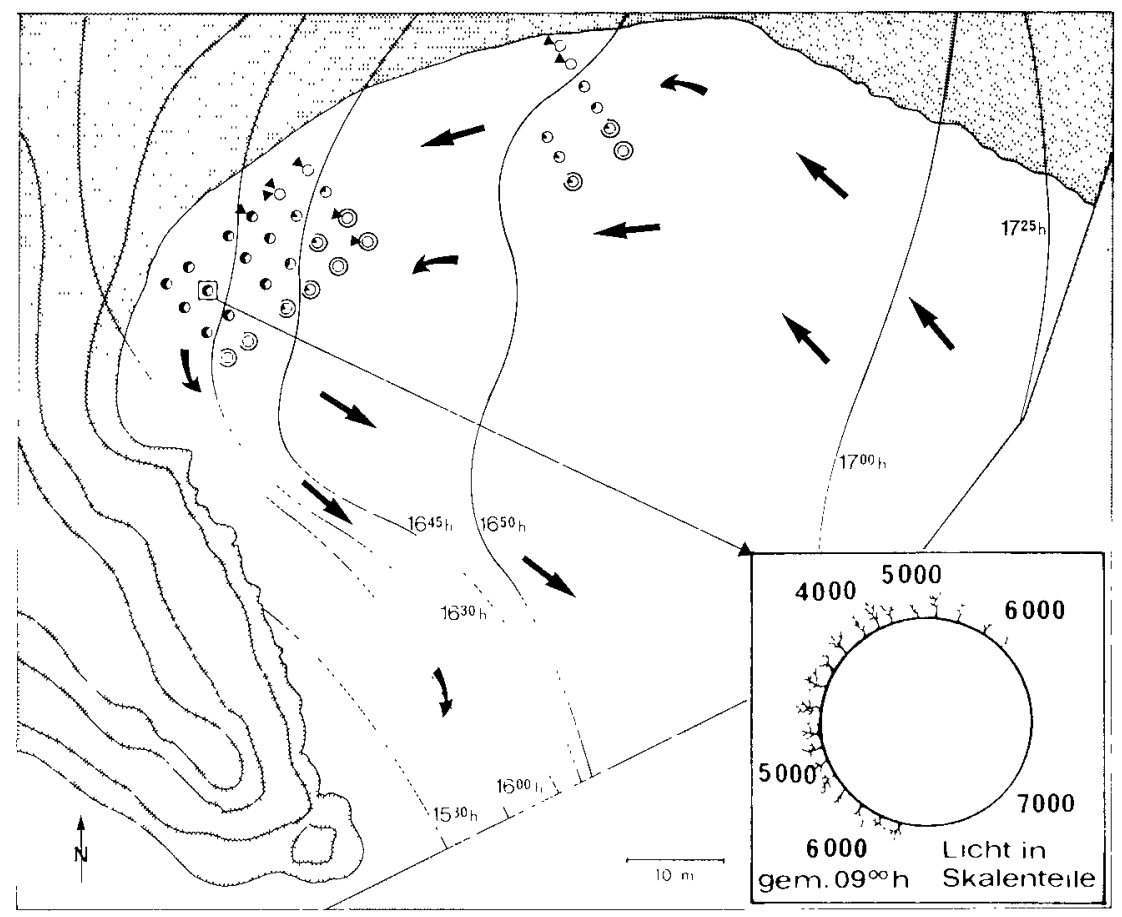

Abb. 19: Horizontale Zonierung von Hydroidenbeständen (Eudendrium carneum = schwarze Sektoren; Halocordyle disticha = konzentrische Linien; Halecium bermuderse = schwarze Dreiecke) an den Säulen eines Bootshauses in der Enseneda de Taganquilla. Die Linien mit den Uhrzeiten geben die zeitlich entsprechenden Schattengrenzen an. Dic schwarzen Pfeile verdeutlichen die Strömungsrichtung. Rechts unten ist eine Säule mit ihrem Bewuchs an Eudendrium carneum herausgezeichnet. Die Kolonien stehen im Schatten der Morgensonne. Gegen Abend wird der Bestand vom Ufer aus beschattet

dyle eingenommen. Weiterhin war festzustellen, daß die Bewuchsflächen und Bestandsdichte von NO nach SW größer wurden (Abb. 19). Für die Untersuchung war es günstig, daß alle Bestände im gleichen Niveau $(0,5-2 \mathrm{~m})$, aber voneinander getrennt wuchsen. Eine Beeinflussung von Biotop zu Biotop war also nicht möglich. Beim Vergleich der Bestände aller Säulen konnte man erkennen, daß es Faktoren geben mußte, die direkt oder indirekt verantwortlich waren für die Orientierung des Bestandes im Raum, die Ausdehnung des Bestandes und die Abundanz des Bestandes.

Von allen ökologischen Faktoren konnten nur Wasserbewegung und Licht eine 
abgestufte Differenzierung im Aufbau von Beständen bewirken, da sie als einzige Faktoren über einen größeren Zeitraum und von Ort zu Ort in unterschiedlicher Intensität auf einen Standort einwirkten. Die Zonierungen innerhalb der Säulengruppen (Halocordyle-Eudendritum) war mit auf die Bewegungsexposition zurückzuführen. Außerdem konnte man die extrem starke Ausbildung der Eudendrium-Kolonien in der linken oberen Ecke von Abbildung 19 auch mit Sicherheit auf ein höheres Nahrungsangebot auf Grund der Wasserbewegung in Verbindung bringen. Die übermäßige Veralgung durch Enteromorpha lingulata war die Hauptursache für die verschieden starke Ausbildung der Eudendrium-Bestände, d. h. letztlich das Licht und seine Auswirkungen.

Abbildung 19 zeigt rechts unten den Querschnitt einer Säule, die zum Teil mit Eudendrium bewachsen war. Der übrige Teil war veralgt. Ebenso waren die Kolonien am Rande des Biotopes veralgt. Alle anderen mit Eudendrium bewachsenen Säulen boten das gleiche Bild. Die Eudendrium-Populationen breiteten sich also so weit aus, wie es die Algen zuließen. Die Beschattung erfolgte hier ebenfalls durch die Uferlandschaft (Abb. 19). Der Einfallswinkel des Lichtes wurde gegen Mittag hin größer und gegen Abend schnell kleiner. Der Schatten, den die Halbinsel Punta de Betin ab etwa $16.00 \mathrm{~h}$ warf, breitete sich infolge des schnell abnehmenden Einfallswinkels der Sonne rasch über die Biotope aus. So wurden die westlichen Seiten der Säulen nur kurz mit direktem Licht versorgt. Der Konkurrenzdruck der Algen war für die dort lebenden Eudendrium-Kolonien nicht so groß, als daß diese am Wachstum gehindert wurden. Die länger beleuchteten Regionen wurden von Halocordyle disticha eingenommen.

Man kann das hier vorliegende Beispiel als einfachen Modellfall ansehen, wie er in

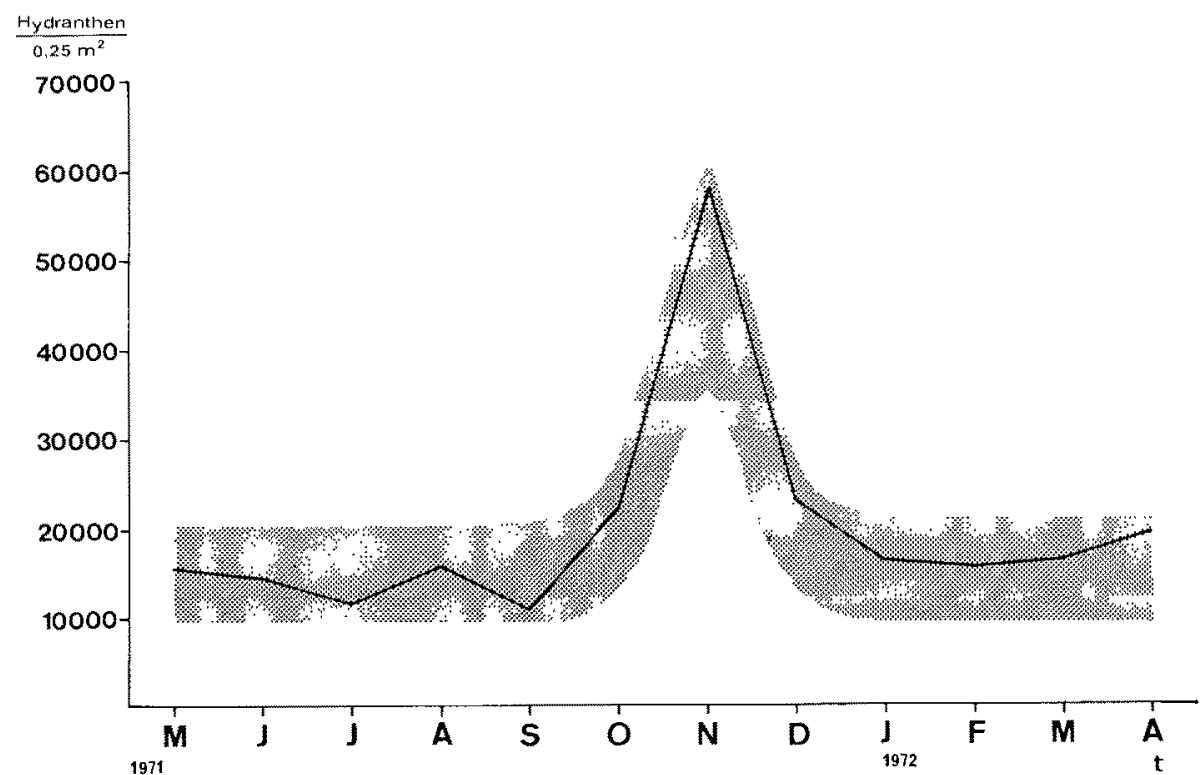

Abb. 20: Abundanzdynamik einer Population von Sertularella speciosa an einer Felsmauer westlich von Punta de Betin. Dünne Linie: Meßkurve der monatlichen Registrierungen. Breites Band: Täglicher Schwankungsbereich (festgelegt durch Kontrollmessungen) 
meist komplizierteren Varianten auf alle Standorte im Litoral übertragen werden kann: Die Lichtenergie pro Fläche und Zeit ist verantwortlich für die Intensität des Algenwuchses und somit auch für den Konkurrenzdruck der Algen gegenüber den Hydroiden. Daher wird die räumliche Orientierung des Algenbestandes, und damit auch die Abgrenzung des Hydroidenbestandes gegen letzteren, durch die räumliche Veränderung des Lichtenergieeinfalles bestimmt. Der Lichteinfall wiederum hängt von der Sonnenbahn, der Jahreszeit und den schattenbildenden Hindernissen ab.

Beziehungen $z$ wischen $A b u n d a n z d y n a m i k u n d$ jährlichem Wechselder Lichtintensität

Bei der Registrierung der Abundanzdynamik einiger Hydroidenbestände wurde u. a. eine Population von Sertularella speciosa erfaßt, die an einer Felsmauer vor

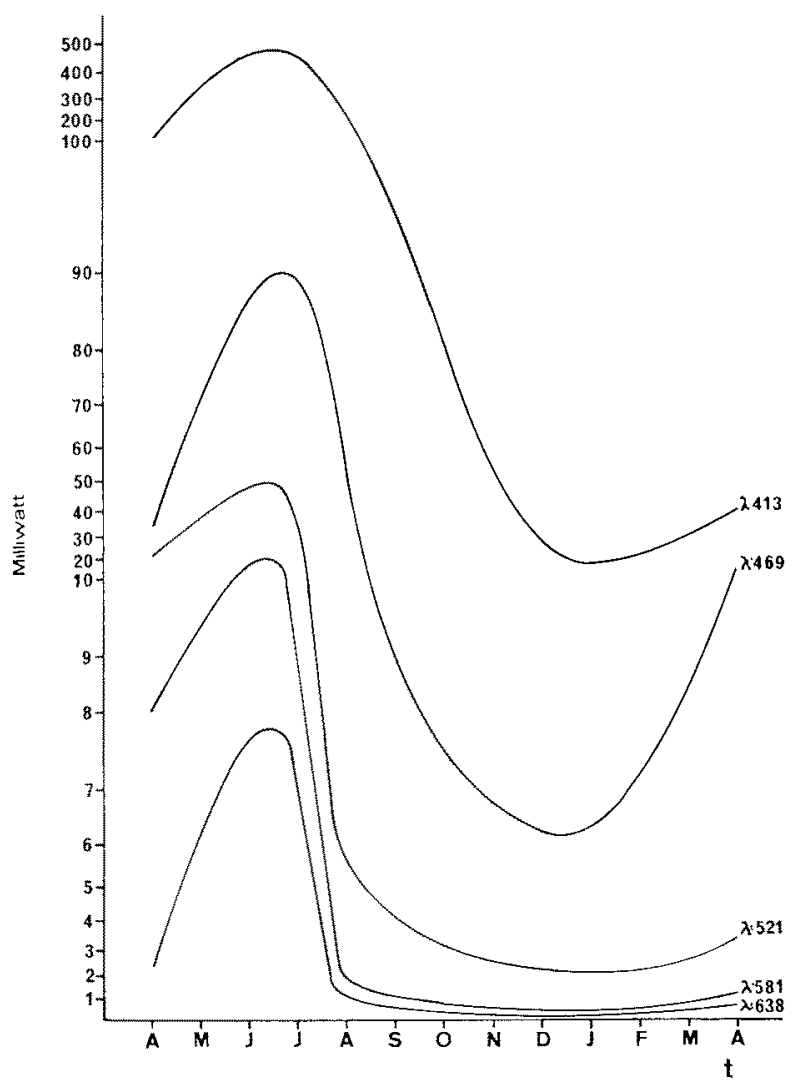

Abb. 21: Der Einfluß des Lichtes auf eine Hydroiden-Population (Sertularella speciosa, vgl. Abb. 20) des Felslitorals im Laufe eines Jahres. (Die Messungen wurden jeweils um $12.00 \mathrm{Uhr}$ über eine Fläche von $15 \mathrm{~cm}^{2}$ vorgenommen) 
Punta de Betin in 2,5 m Tiefe über den ganzen Zeitraum der Untersuchungen hinweg existierte. Da diese Hydroiden ständig von kleinen Rotalgen (Ceramium spec.) überwachsen wurden, zogen sie jeweils ihre am heftigsten befallenen Kolonien ein, um sofort neue Kolonien auszutreiben. Daher schwankte die tägliche Abundanz der Hydranthen zwischen 10000 und 20000 Köpfchen. Im Oktober jedoch stieg die Zahl

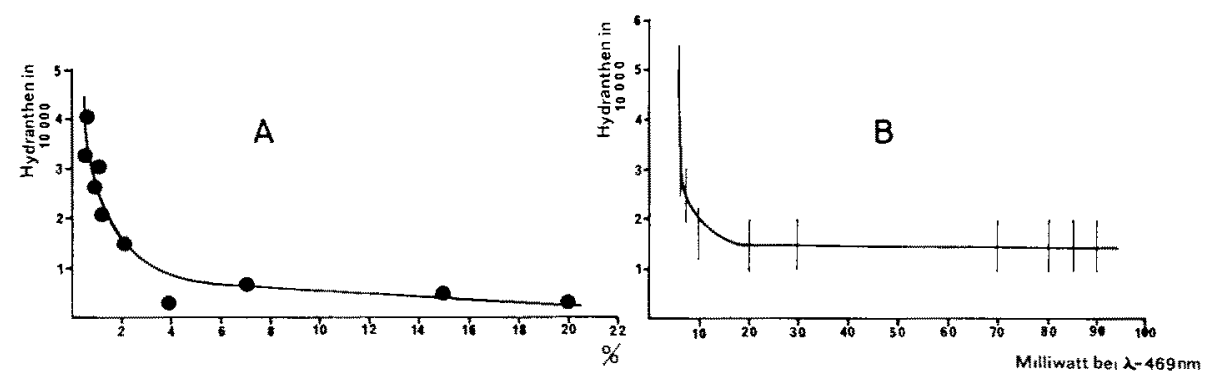

Abb. 22: (A) Dichte eines Bestandes von Sertularia inflata in Relation zum einfallenden Licht, dargestellt in \% zum Lichtmaximum über der Wasseroberfläche. (B) Dichte eines Bestandes von Sertwlarella speciosa in Relation zum Licht, dargestellt durch die bei einem bestimmten Spektralbereich auf eine konstante Fläche einwirkende Energie

der Hydranthen steil an und erreichte im November fast 60000 (vgl. Abb. 20, 22 B). Erst gegen Dezember hin sank diese Zahl wieder rasch ab und pendelte sich im Januar auf die ursprünglichen Werte ein.

Durch die Pendelbewegung der Sonnenbahn war im Dezember (Sonnenwende) die Sonne am weitesten von dem Sertularella-Bestand entfernt. In dieser Zeit erhielt der Biotop die geringste Lichtmenge. Im Juni hingegen übte sie ihren größten Einfluß auf den Bestand aus. Lichtmessungen, die in diesem Biotop durchgeführt wurden, verdeutlichen diesen Wechsel (Abb. 21). Im Juni herrschte zwar die stärkste Einstrahlung an Lichtenergie, jedoch verhinderte die bereits erwähnte Anpassungsfähigkeit dieser $\mathrm{Hy}-$ droiden an den intensiven Algenbefall, daß in dieser Zeit die Abundanzkurve abfiel.

$$
\begin{gathered}
\text { Jährliche Schwankungdes Dispersionsbildes } \\
\text { eines Bestandesvon Sertularellaspeciosa }
\end{gathered}
$$

Der untersuchte Biotop lag an der Nordseite der Felsmauer westlich von Punta de Betin in 2-2,5 m Tiefe. Die Ausmaße des Untersuchungsquadrates betrugen $50 \times 50 \mathrm{~cm}$. Folgende Beobachtungen wurden im Laufe eines Jahres gemacht (vgl. Abb. 23): (1) Der Bestand an Halopteris carinata blieb in Dichte und Ort konstant. (2) Der Bestand an Eudendrium carneum blieb örtlich konstant, zeigte aber eine Veränderung in der Dichte mit dem Maximum vom Oktober bis Dezember. (3) Die Bestände an Halocordyle disticha hatten im November bis Dezember den Höhepunkt ihrer Abundanz. Die Dispersion bewegte sich immer um einen konstanten Bereich. (4) Die Population von Sertularella speciosa bildet innerhalb der Biozönose Gruppen, die örtlich konstant blieben. Es veränderte sich nur die Abundanz und die Größe der Stöckchen. Das Maximum lag auch hier im November. 


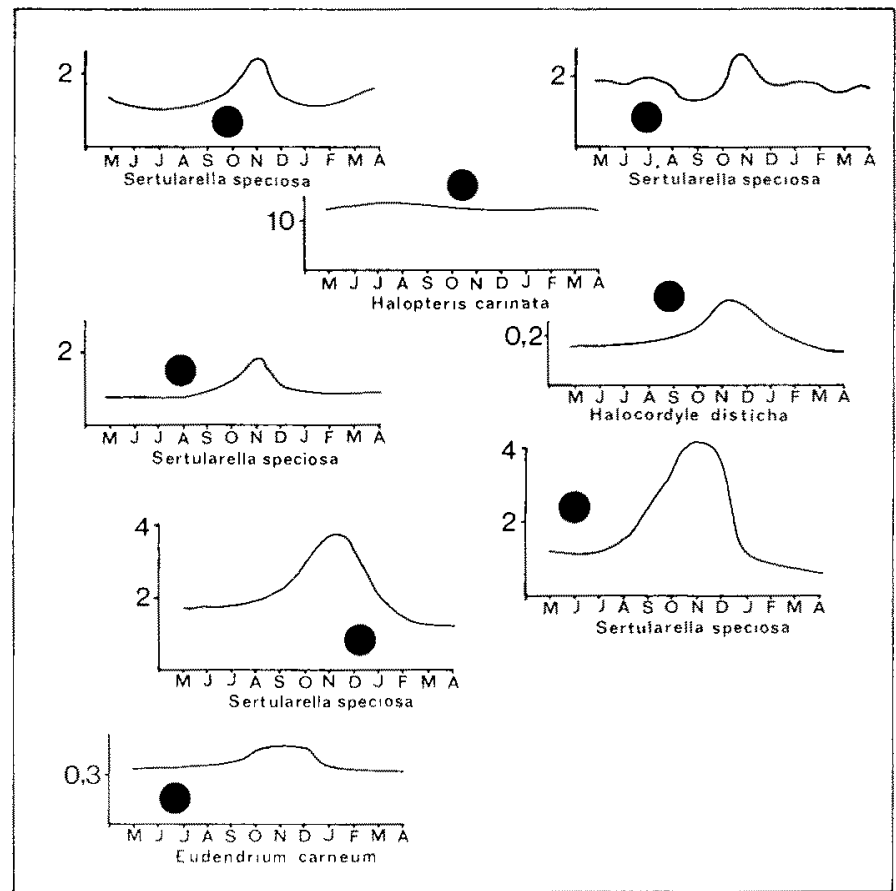

Abb. 23: Dispersionsbild an einer Felsmauer in einer Tiefe von $2-3 \mathrm{~m}$. Das Diagramm zeigt die Verteilung (schwarze Punkte) von verschiedenen Hydroidenkolonien auf einer Flache von $50 \times 50 \mathrm{~cm}$. Die Kurven veranshaulichen die Schwankung der jeweiligen Koloniestirke über die Zeit vom Mai 1971 bis zum April 1972. Die Koloniestärke ist jeweils auf der Ordinate in 1000 Hydranthen festgelegt

\section{Aktivitätswechsel und Reifeperiode}

Viele Hydroidenkolonien wurden dauernd auf ihre Aktivität hin kontrolliert. Es interessierte, in welchem Rhythmus folgende drei Phasen aufraten: (a) $\mathrm{R} \mathrm{uh} \mathrm{e-}$ $\mathrm{ph}$ a se oder Me non te $\mathrm{n}$ phase (die Hydroidpolypenkolonien bestehen nur als Reste von Hydrocauli oder Stolonen); (b) Veget ationsphase (Polypen mit Hydranthen in der Wachstumsperiode); (c) Reifephase (Polypen mit Gonophoren).

Ruhephasen konnten besonders bei aestuarinen Hydroiden wie Cordylophora caspia und Calyptospadix cerula festgestellt werden. Sie überbrïken in der Menontenphase extreme Süß-bzw. Salzwasserperioden (KInNe, 1955, 1956; Wedler, 1974). Die vegetative Aktivitätsphase war bei verschiedenen Hydroiden von unterschiedlicher Dauer. So lebten eine große Zahl an Campunulariden und Plumulariden nur bis ein paar Wochen, während Sertularella speciosa, Cnidoscyphus marginatus und Halopteris carinata sich in der gesamten Untersuchungszeit am gleichen Standort zeigten (Tab. 4).

Bei Tabelle 4 ist zu beachten, daß die Phasen von Standort zu Standort verschieden lagen und unterschiedlich lang sein konnten. An ruhigeren Standorten hielt sich das 


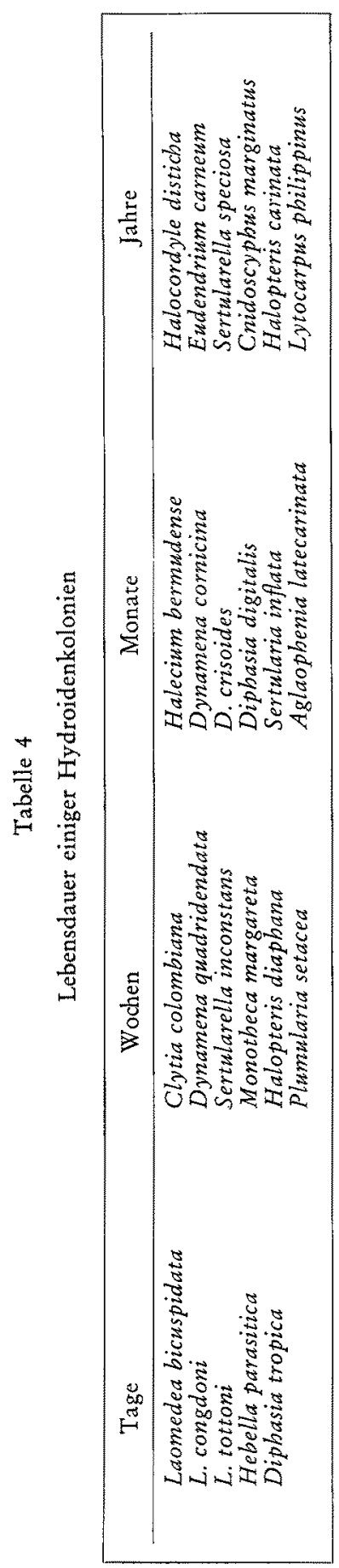


Bestandsbild einer gleichen Art länger als in einer bewegten Umgebung. Sertularia inflata z. B. wurde in einer Blockhöhle länger als ein Jahr vorgefunden. Als Epizoe auf Sargassum in der Brandungszone hielt sich der Bestand nur Wochen bis Monate. Ebenso verhielt es sich mit Halocordyle disticha und Halecium bermudense. Während sich die Bestände in ruhigen Regionen über Monate bis Jahre hielten (in der Strömungszone und unter Kunstbauten), existierten im exponierten Felslitoral die wesentlich kleineren Formen der gleichen Arten nur Wochen bis Monate. Der Grund für die unterschiedlichen Eingrenzungen der Aktivitätsphasen lag naturgemäß in den ökologischen Bedingungen. Alle Hydroiden mit einer kürzeren Aktivitätsphase lebten in einer physikalisch oder biologisch dynamischen Umgebung und wurden zeitlich verschieden stark beeinflußt bzw. als Epizoen auf Pflanzen oder sessilen Tieren und waren somit an die zeitlich begrenzte Existenz ihres lebenden Substrates gebunden. Je konstanter und damit ungestörter die Umweltbedingungen waren, desto länger dauerte die Vegetationsperiode. Kurzzeitige Veränderungen innerhalb einer Biozönose oder zwischen den Aktivitätsphasen wurden meistens durch spontane abiotische oder biotische Einflüsse veranlaßt. Die Hydroiden konnten sich immer auf plötzlich auftretende ungünstige Verhältnisse einstellen. Dies geschah z. B. durch Abwerfen von befallenen Cladien oder Kolonien

Tabelle 5

Reifephasen einiger Hydroiden vor Santa Marta (Kolumbien)

\begin{tabular}{|c|c|c|c|c|c|c|c|c|c|c|c|c|c|c|c|c|}
\hline \multirow{2}{*}{ Hydroiden-Species } & \multicolumn{12}{|c|}{1971} & \multicolumn{4}{|c|}{1972} \\
\hline & J & F & $\mathrm{M}$ & A & M & $\mathrm{J}$ & $\mathrm{J}$ & A & $\mathrm{S}$ & $\mathrm{O}$ & $\mathrm{N}$ & $\mathrm{D}$ & $J$ & $\mathrm{~F}$ & M & A \\
\hline Calyptospadix cerula & & & & & & $+\frac{1}{t}$ & + & + & + & & & & & & & \\
\hline Eudendrium carneum & & + & + & $\dashv$ & + & + & + & + & + & & & & & & + & + \\
\hline Eudendrium capillare & + & + & + & + & + & & & & & & & & + & + & + & + \\
\hline Halecium bermudense & & & t & & & & & & + & & & & $t$ & + & & \\
\hline Diphasia digitalis & & & + & & & & & & & + & + & & & + & & \\
\hline Dynamena cornicina & + & + & & & & & & & & & & & + & & & \\
\hline Dynamena crisoides & & & & & & & + & & & & & & & & & \\
\hline Dynamena quadridendata & & & t. & & & & & & & & & & & & & \\
\hline Cnidoscypbus marginatus & & & & & & & + & & & & & & & & & \\
\hline Sertularella inconstans & & & + & + & + & & & & & & & & & & & \\
\hline Sertularella speciosa & & & & & + & + & + & & & + & + & & & & & \\
\hline Plumularia setacea & & & & + & + & + & & & & & & & & & & \\
\hline Aglaophenia latecarinata & & & & & & + & & & & & & & & & & \\
\hline Lytocarpus philippinus & & & & + & + & & + & + & + & & & & & & & \\
\hline
\end{tabular}

und anschließender Regeneration oder Neubesiedlung (vgl. TARdent, 1965). Jahreszeitliche Schwankungen der Reifezeiten auf Grund ökologischer Veränderungen ließen sich kaum feststellen. Jedoch zeigte im Mai 1971 der größte Teil aller Hydroiden Reifestadien (Tab. 5).

Möglicherweise stand dies mit der Änderung der Wassertemperatur in Verbindung (Abb. 3). Der Kurvenverlauf des Salzgehaltes ließ jedenfalls keinen Rückschluß\} auf einen Zusammenhang zwischen Salinität und Fortpflanzung zu. Dies dürfte nur für aestuarine Arten wie Cordylophora caspia und Calyptospadix cerula gelten. Eudendrium carneum ließ vor Santa Marta keine einheitliche Reifeperiode erkennen, sondern wies wie viele andere tropische Litoralbewohner von Standort zu Standort unter- 
schiedliche Reifezeiten auf (Abb. 24). Es war deshalb nicht einfach, das Einsetzen der Reifeperiode bestimmten klimatischen Bedingungen zuzuordnen. Offensichtlich lagen in jedem Standort die ökologischen Faktoren in unterschiedlichen Phasen vor. Nicht nur der Einsatz der Reifezeiten, auch die Dauer der Reifephasen war je nach Standort

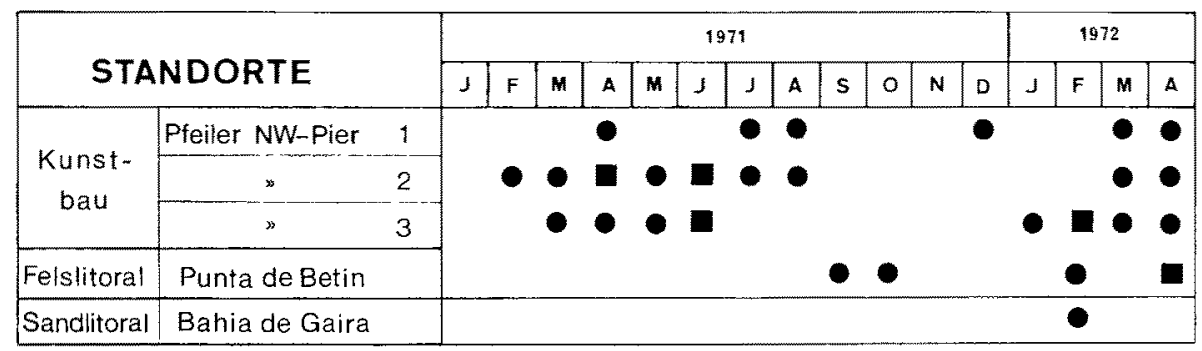

Abb. 24: Zeitlich unterschiedliches Auftreten von Gonophoren (Punkt: $q+\hat{o}$, Quadrat: $\hat{o}$ ) bei Eudendrium carneum an verschiedenen Standorten

unterschiedlich (Tab. 6). Auch hier zeigte sich die gleiche Tendenz: Kurzphasische ökologische Schwankungen waren mit kurzer Reifedauer, langphasische ökologische Schwankungen mit langer Reifedauer korreliert. Am Beispiel von Sertularella speciosa ließ sich weiterhin erkennen (Tab. 6), wie sich die zeitlich unterschiedlichen ökologischen Abläufe auch auf das Wachstum und die Reifeperiode (nicht nur Reifedauer) auswirkten.

Tabelle 6

Reifezeiten und Reifedauer einiger Sertularella speciosa-Populationen

\begin{tabular}{|c|c|c|c|c|c|c|}
\hline \multicolumn{2}{|c|}{ Ort und Tiefe (m) } & \multirow{2}{*}{$\begin{array}{l}\text { Wasserbewegung } \\
\text { laminar, ruhig }\end{array}$} & \multirow{2}{*}{$\begin{array}{l}\text { Licht- } \\
\text { exposition }\end{array}$} & \multirow{2}{*}{$\frac{\begin{array}{l}\text { Kolonie- } \\
\text { länge }\end{array}}{18 \mathrm{~cm}}$} & \multirow{2}{*}{$\frac{\text { Reifezeit }}{\text { Mai-Juli }}$} & \multirow{2}{*}{$\begin{array}{l}\text { Reifedauer } \\
\text { etwa 50 Tage }\end{array}$} \\
\hline & & & & & & \\
\hline $\mathrm{Fe}$ & $15-30$ & & Halbschatten & $18 \mathrm{~cm}$ & Mai-Juli & etwa 50 Tage \\
\hline Felslitoral & $6-10$ & endelnd & Schatten & $12-16 \mathrm{~cm}$ & Juni- & etwa 40 Tage \\
\hline Felslitoral & $3-5$ & schwi & Halbschatten & $8-12 \mathrm{~cm}$ & Oktober & 6 Tage \\
\hline Felslitoral & $2-3$ & schwingend & Halbschatten & $6-8 \mathrm{~cm}$ & November & 4 Tage \\
\hline Felslitoral & $2-3$ & stark schwingend & Halbschatten & $4-6 \mathrm{~cm}$ & Okt.-Nov. & 2-4 Tage \\
\hline & $4-5$ & schwingen & Halbschatten & $8-12 \mathrm{~cm}$ & November & 5 Tage \\
\hline
\end{tabular}

\section{Variabilität der Hydroidpolypen in Form und Größe}

Durch verschiedene ökologische Einflüsse variieren stockbildende Hydroiden in ihrem räumlichen Aufbau und ihrer Größe (RIEdr, 1959, 1964) (Abb. 25). Es zeigte sich, daß die stockbildenden Kolonien stets bestrebt waren, einen möglichst großen Wasserkörper zu durchfiltern. Es konnte kein Faktor ermittelt werden, der das Größenwachstum entscheidend beeinflußt, sondern nur eine Reihe günstiger Umwelt- 


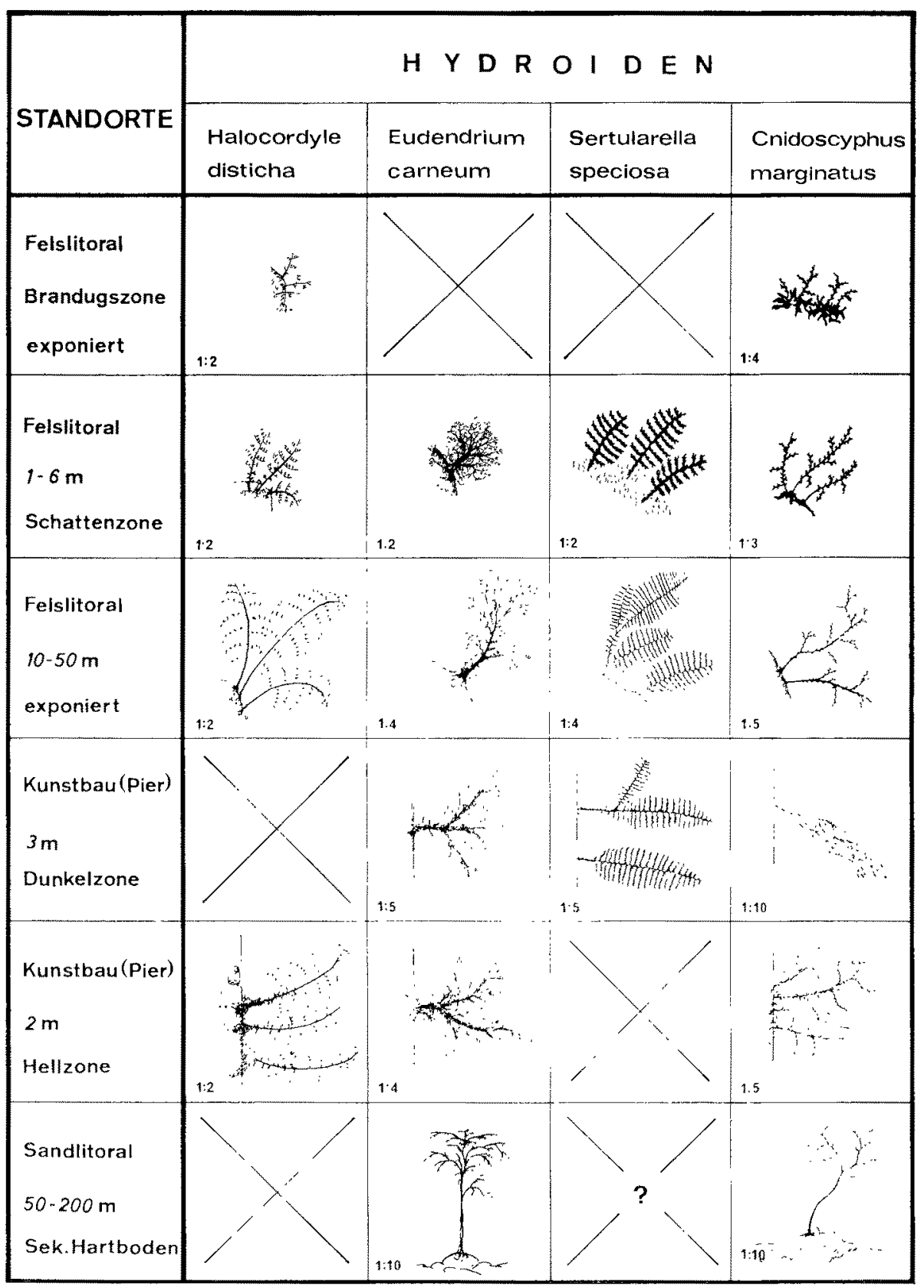

Abb. 25: Bezichung zwischen Wuchsform und Koloniegröße zum Standort bei cinigen Hydroidpolypen 
bedingungen, die das Wachstum zulassen oder gar fördern. Die verschiedenartigen Formen und Größen von Stöckchen aus unterschiedlichen Tiefen hingen nur von Faktoren $\mathrm{ab}$, die sich eben dort unterschiedlich auswirkten. Die Wassertiefe selbst hatte nur einen topographischen Wert (Abb. 26, 27). Der Expositionsgrad stellte ebenfalls immer
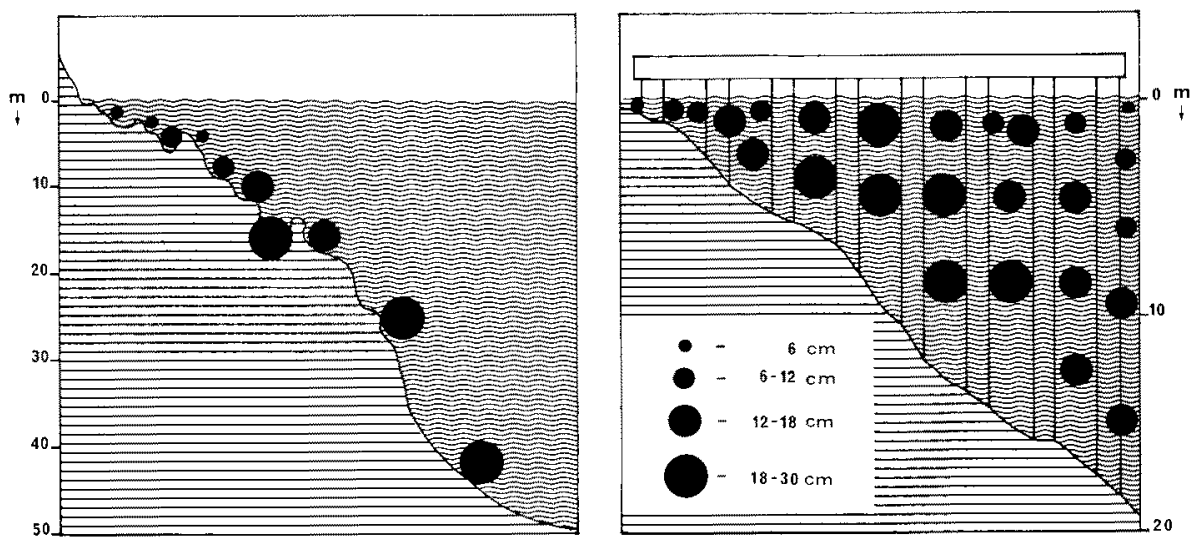

Abb. 26: Verteilung der unterschiedlichen Wuchsgrößen von Eudendrium carneum im Felslitoral (links) und unter dem Kunstbau (rechts)

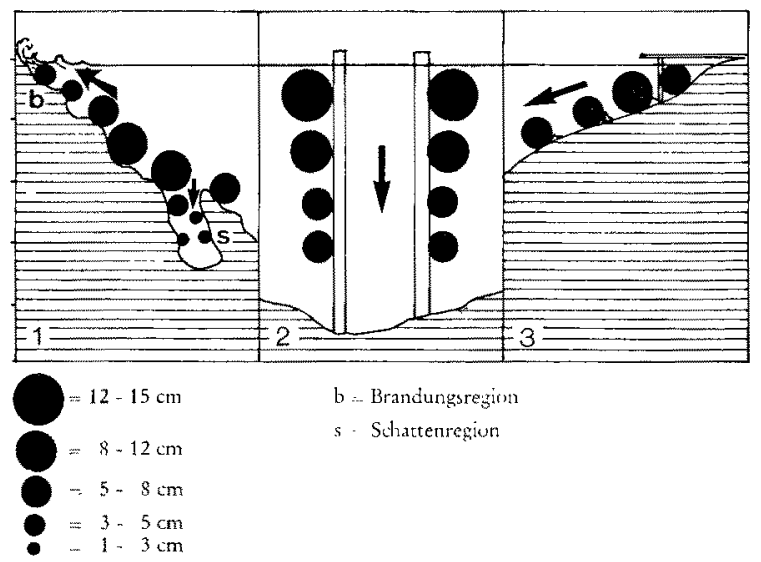

Abb. 27: Verteilung der unterschiedlichen Wuchsgrößen von Halocordyle disticha im Felslitoral (1), unter dem Kunstbau (2) und im Sandlitoral (3) Pfeil = Richtung der Abweichung vom Optimaltypus

nur eine örtliche Relation zu anderen Faktoren dar. Abweichende Expositionsverhältnisse ließen verschiedene physikalische und damit auch biologische Bedingungen zu. Das Substrat spielte eine wichtige Rolle bei der Besiedlung, aber nicht beim Aufbau der Wuchsformen und der Begrenzung der Koloniegröße. Anderenfalls ist aber die Substratneigung in Verbindung mit der Richtung und Stärke der Wasserbewegung mit verantwortlich für die Form und Größe der Kolonie (Abb. $28 \mathrm{~A}, \mathrm{~B}$ ). 
Um den Einfluß der unterschiedlichen hydrodynamischen Bedingungen auf Wuchsgröße und -form zu untersuchen, wurden möglichst viele Standorte im Litoral überprüf, die über einen größeren Zeitraum die gleiche Hydroidenart aufwiesen, unterschiedlichen Bewegungsverhältnissen unterlagen oder bei gleichen Bewegungsverhältnissen durch andere Faktoren (wie z. B. Licht) in unterschiedlicher Intensität beeinflußt wurden. Für die Untersuchungen boten sich vor allem Hydroiden an, die in der Lage waren, einen möglichst großen Verbreitungsbereich zu besiedeln, wie z. B. Cnidos-

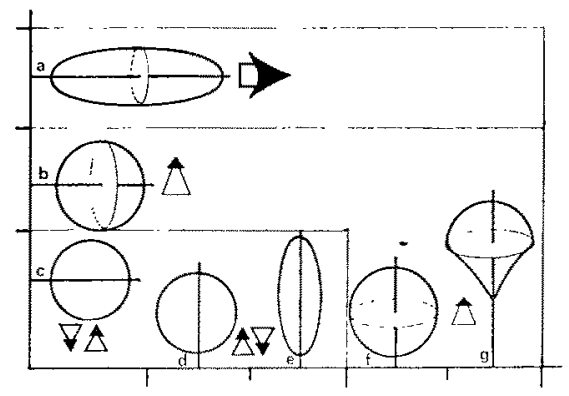

A

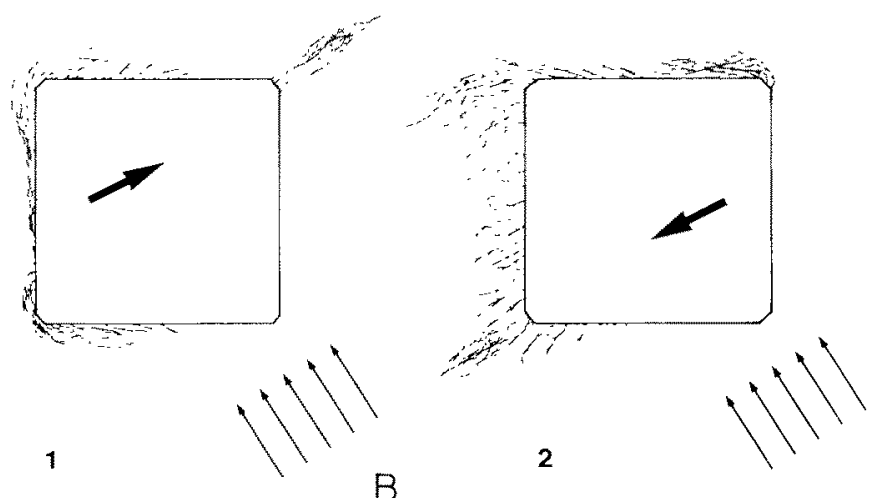

Abb. 28: (A) Räumlicher Kolonieaufbau bei verschiedenen Strömungsbedingungen und unterschiedlicher Substratneigung. Die Pfeile verdeutlichen die Bewegungsart: Ein Pfcil = laminar; zwei Pfeile = pendelnd. Die Kolonien $a, b, f$ und $g$ sind räumlich aufgebaut. Die Kolonien c, d und e sind flächig. (B) Entstehung einer räumlichen "Fahne" an einem senkrechten Pierpfeiler. Der Wasserkörper zieht hier von der Basis der Kolonie zur Spitze. Dicke Pfeile = Strömungsrichtung; dünne Pfeile = Lichteinfall

cyplbus marginatus (Abb. 29). Die Variationsbreite dieser Art bei unterschiedlichen Bewegungsbedingungen war aufällig. Prinzipiell nahm die Länge der Kolonien mit abnehmender Wasserbewegung stark zu (Abb. 30 B). Die Größe der Kolonie, d. h. die Abundanz der Hydranthen, sticg im gleichen Maße (Abb. $30 \mathrm{~A}$ ).

Flächige Kolonien änderten sich unter unterschiedlichen hydrodynamischen Bedingungen meist nur in ihrer Größe (Abb. 31). Immer waren sie senkrecht zur Hauptbewegungsrichtung und zueinander parallel orientiert (vgl. Rreor, 1966). Ein Versuch 
im Labor mit Sertularella speciosa ergab, daß die Stolonen der Kolonien bei flächenmäßiger Vergrößerung des Bestandes sich immer quer zur Strömung ausbreiteten. Aus ihnen trieben wieder neue Kolonien aus, die somit parallel ausgerichtet waren (Abb. 32). Beim Registrieren von Wuchsgrößen mußte auch der Zeitfaktor berücksichtigt werden, wie die Abbildungen 33 und 34 erkennen lassen (vgl. RALPH \& 'THOMSON, 1968).

\section{SCHLUSSBETRACHTUNGEN}

Mit der vorliegenden Arbeit sollten einige Schwerpunkte zur Erforschung der Okologie tropischer Hydroiden gesetzt werden. Insbesondere wurde der Versuch unternommen, den Einfluß der wichtigsten ökologischen Faktoren auf den Wuchs verschie-

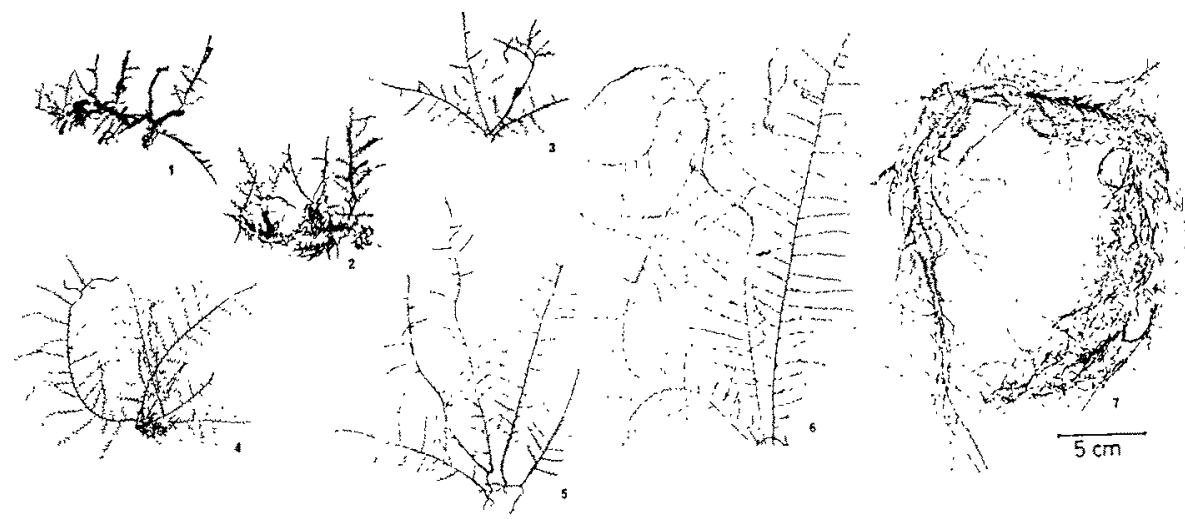

Abb. 29: Unterschiedliche Wuchsformen und Koloniegrößen von Cnidoscyphus marginatus aus verschiedenen Bewegungszonen. 1-2 = Brandungszone, $3-5=$ Schwingungszone, $6=$ Strömungszone und $7=$ "Fahne" aus der Strömungszone unter dem Kunstbau. Die Abbildung zeigt verkleinerte Kopien lebender Kolonien
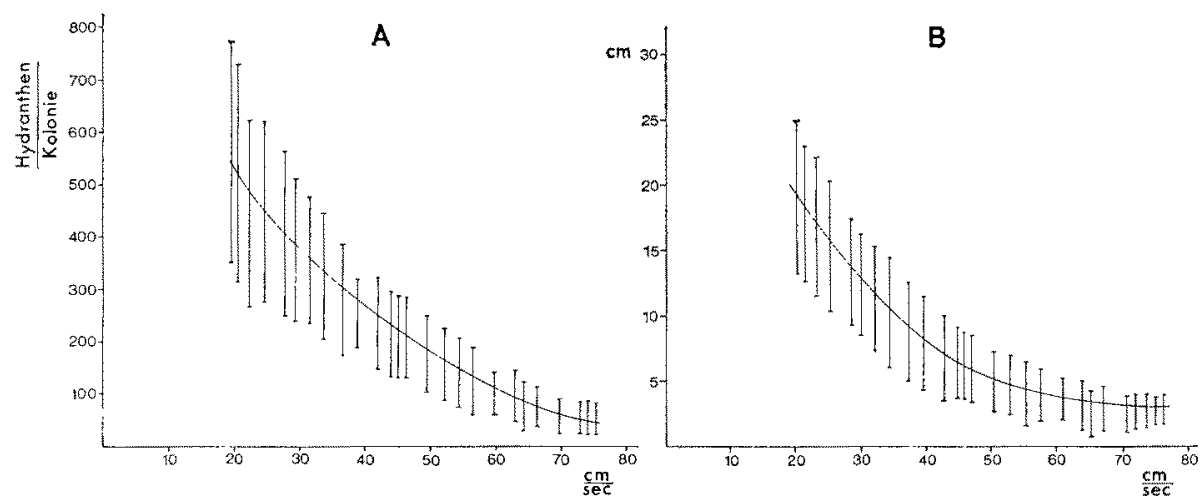

Abb. 30: (A) Veränderung der Koloniegröße von Cnidoscyphus marginatus bei verschieden starker Wasserbewegung. (B) Länge der Stöckchen von Cnidoscyphus marginatus bei verschieden starker Wasserbewegung. Die senkrechten Linien auf den beiden Kurven geben den Bereich der Standardabweichung in den jeweiligen Meßfeldern an 


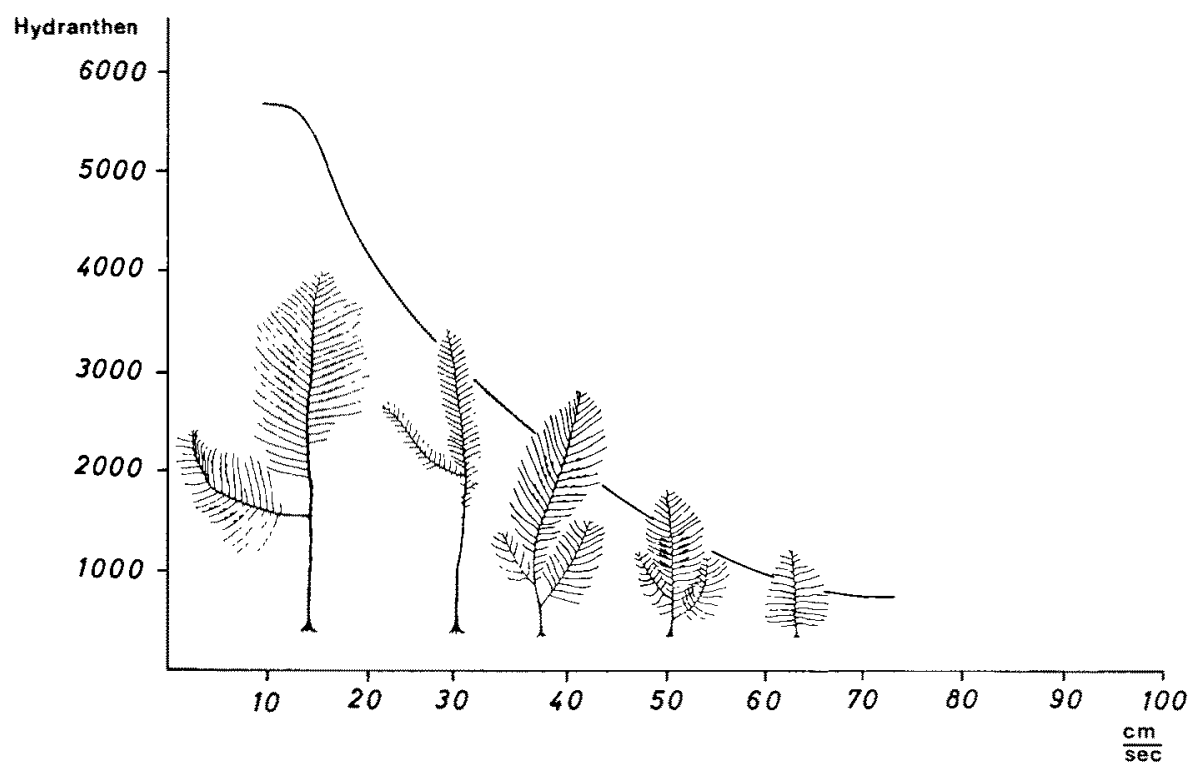

Abb. 31: Wuchsbild einer flächigen Hydroidenkolonie (Sertularella speciosa) bei unterschiedlich starker Wasserbewegung

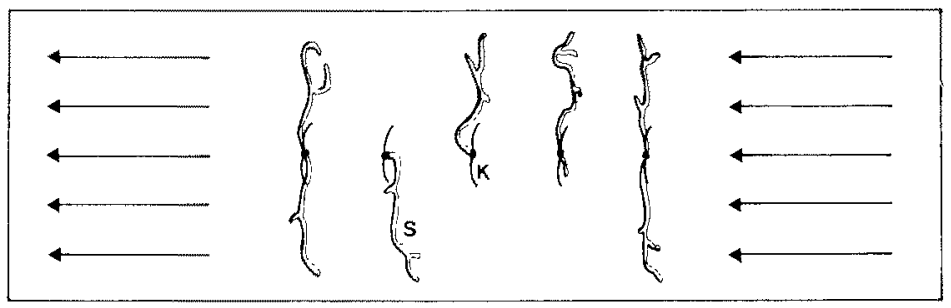

Abb. 32: Strömungsversuch mit einem zweidimensional ausgerichteten Hydroidpolvp (Sertularella speciosa). Die Stolonen (S) der Kolonien (K) wuchsen immer senkrecht zur Strömungsrichtung (Pfeile)

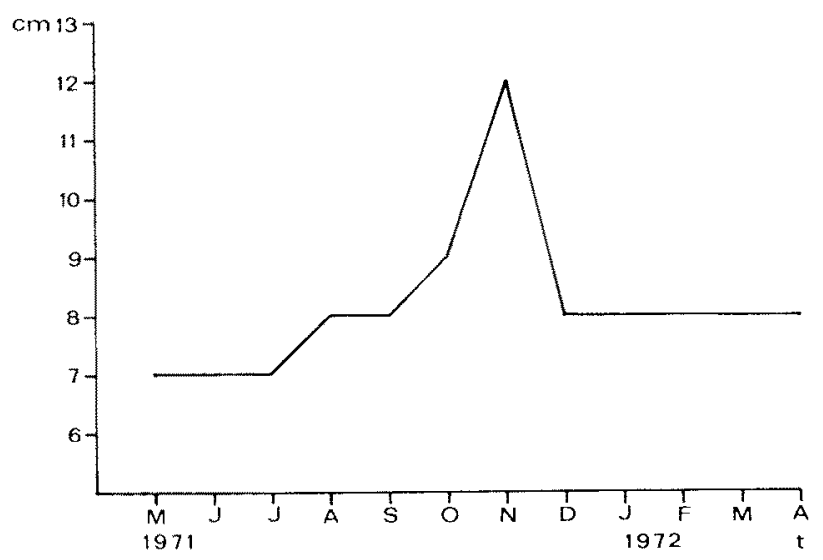

Abb. 33: Veränderung der durchschnittlichen Länge von Kolonien einer Sertularella speciosaPopulation im Laufe eines Jahres 
dener Hydroidenarten $z u$ analysieren. Während der Durchführung der Freilanduntersuchungen wurden die Schwierigkeiten deutlich, die Rolle der einzelnen Umweltfaktoren sowie ihr Zusammenwirken zu erfassen. Daraus erklärt sich auch, daß bisherige ökologische Arbeiten an Hydroiden des Felslitorals lediglich Bestandsaufnahmen darstellten (RIedl, 1959; Mergner, 1967) und Aussagen zur Okologie der Hydroiden entweder nur kurzen Bemerkungen innerhalb umfassender Zonierungsarbeiten oder experimentellen Laboruntersuchungen an Hydroiden (u. a. KINNE, 1955) entnommen werden konnten.

Im Rahmen von Freilanduntersuchungen lassen sich zumeist die einzelnen wirksamen Faktoren nicht ohne weiteres herauslösen und in ihrer Bedeutung analysieren. Daher wurde versucht, Situationen zu finden, in denen ein Faktor innerhalb eines

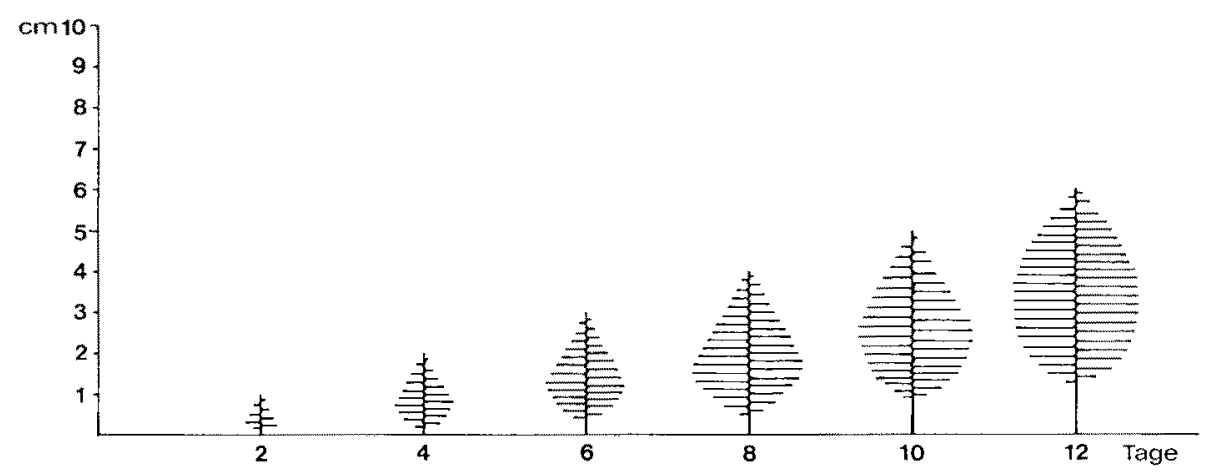

Abb. 34: Durchschnittliche Wuchsgeschwindigkeit eines Hydroidpolypen (Sertularella speciosa) bei einer Wassertemperatur von $24-25^{\circ} \mathrm{C}$

Biotops einen besonders starken Einfluß ausübt, oder aber Abweichungen zwischen verschiedenen Biotopen auftreten, um diesen in seiner räumlichen und zeitlichen Wirkung erfassen zu können.

Eine Untersuchungsdauer von einem Jahr stellt freilich nur das Mindestmaß für ökologische Untersuchungen im Freiland dar. Für differenziertere Aussagen muß dagegen das ökologische Erscheinungsbild innerhalb bestimmter Biotope über eine Reihe von Jahren verfolgt werden. Dazu sind weitere vertiefte Untersuchungen notwendig, die sich u. a. zuwenden sollten dem Einfluß biotischer und abiotischer Faktoren auf die Populationsdynamik und den Aktivitätswechsel während mehrerer Jahreszyklen, den Präferenzbereichen und Toleranzgrenzen, Ursachen und Entstehung der Zonierungen, den Wechselbeziehungen zwischen Hydroiden- und Poriferenarten, dem Einfluß des Standortes auf die Fortpflanzungs- und Verbreitungsformen, den Reifezeiten und ihre auslösenden Faktoren, der Rolle des Lichtes für die Koloniebildung und dem Einfluß des Futterangebotes auf die Wuchsform. Die vorstehend genannten Aspekte sollen experimentell in weiterführenden Studien - teils im Freiland, teils in Laboruntersuchungen - angegangen werden. 


\section{ZUSAMMENFASSUNG}

1. Im Litoral der Nordküste Kolumbiens wurden ökologische Untersuchungen an Hydroiden, von denen ca. 90 Arten gefunden wurden, über einen Zeitraum von 16 Monaten in Zusammenhang mit Messungen verschiedener Umweltfaktoren (Licht, Wasserbewegung, Temperatur, Salzgehalt u. a.) durchgeführt. Zur Ergänzung der Studien im Felslitoral und für vergleichende Betrachtungen wurden Sandlitoralgebiete und Kunstbauten mit einbezogen.

2. Bestimmte Hydroiden besiedeln bevorzugt charakteristische Substrate. Sie orientieren sich in artspezifischer Weise nach dem Licht, der Form und Beschaffenheit des Untergrundes und nach der Schwerkraft. Bei der Besiedlung neuer Substrate treten zuerst Arten mit kurzer Entwicklungsperiode auf. Dann folgen - je nach Jahreszeit - Arten mit längeren Lebenszyklen.

3. Die Abgrenzung der Lebensräume der einzelnen Hydroidenarten ist vornehmlich durch exogene Faktoren bedingt. Sie hängt $a b$ von der Häufigkeit des Wasseraustausches pro Zeit-Volumeneinheit, der Intensität des Lichtes und des damit verbundenen Algenwuchses. Mit dem jahreszeitlichen Wechsel des Lichteinfalles und der Lichtintensität verändern sich die Grenzen der einzelnen Hydroidbiotope ebenfalls. Umsetzungsversuche ergaben, daß die meisten Hydroidenarten ein größeres autökologisches Potential besitzen, als im synökologischen Gefüge deutlich wird. Einige Hydroidenspecies (wie z. B. Cnidoscyphus marginatus) sind in bezug auf die Wasserbewegung (und in etwas geringerem Maße in bezug auf das Licht) euryök.

4. Mit zunehmender Wassertiefe nimmt die Abundanz der Arten ab. Es kann zwischen kurzzeitigem und langzeitigem Aktivitätswechsel unterschicden werden. Bei kurzzeitigem Wechsel entzieht sich die Kolonie ungünstigen Bedingungen durch Abwurf der Cladien, um erst unter günstigeren Umweltbedingungen wieder auszutreiben. Ein langzeitiger Wechsel (von der Menontenphase zur Vegetationsphase) steht of in Verbindung mit langphasischen Umweltveränderungen. Die Reifezeiten vieler Arten sind abhängig vom jeweiligen Standort. Mit zunehmender Tiefe bzw. mit abnehmender Wasserbewegung nimmt die Reifedauer zu.

5. Viele Hydroiden passen sich in Form und Größe unterschiedlichen ökologischen Bedingungen an, wobei die Wasserbewegung als der wichtigste beeinflussende Faktor anzusehen ist. Daneben bestimmen aber auch Licht, Beifauna, Epizoen und andere Faktoren die Formgebung der Hydroidenkolonie.

Danksagung: Für die Anregung zu dieser Arbeit und die Unterstützung bei der Durchführung danke ich Herm Prof. Dr. H. Mergner. Weiterhin danke ich Herrn Dr. R. KaufMANN, dem ehemaligen Leiter des Instituto Colombo-Aleman in Santa Marta. Er stellte mir jederzeit die Arbeitsgeräte seines Institutes zur Verfügung. Außerdem gilt mein Dank Herrn Dipl.-Ing. G. SENNER, der mir dic erforderlichen Meßgeräte konstruierte. Besonderen Dank schulde ich dem DAAD, der durch seine finanzielle Unterstützung den Aufenthalt in Santa Marta (Kolumbien) ermöglichte.

\section{ZITIERTE LITERATUR}

Böhnecke, G., 1936. Temperatur, Salzgehalt und Dichte an der Oberfläche des Atlantischen Ozeans. Wiss, Ergebn. dt. atlant. Exped. „Meteor" 5 (Atlas). 
Clarke, S. F., 1879. Report on the Hydroida collected during the exploration of the Gulf Stream and of Mexico by A. AgAssiz 1877-1878. Bull. Mus. comp. Zool. Harv. 5, 239-252.

-1882 . New and interesting hydroids from Chesapeake Bay. Mem. Boston Soc. nat. Hist. 3 (4), 135-142.

Coe, W. R., 1932. Season of attachment and rate of growth of sedentary marine organisms at the pier of the Scripps Institution of Oceanography, La Jolla, California. Bull. Scripps Inst. Oceanogr., tech. Ser. 3 (3), 37-86, pl. 1-6.

Congdon, E., 1907. The Hydroids of Bermuda. Proc. Am. Acad. Arts Sci. 42, 461-485.

DA.HL, E, 1953. Some aspects of the biology and zonation of the fauna of sandy beaches. Oikos 4, 1027 .

Fraser, McLean, 1944. Hydroids of the Atlantic coast of North America. University of Toronto Press, Toronto, $640 \mathrm{pp}$.

- 1947. Hydroids of the Allan Hancodk Caribbean Sea expedition 1939. Rep. Allan Hancock Atlant. Exped. 4, 1-24.

HeRrManN, R., 1970. Deutungsversuch der Entstehung der „Brisa“, eines föhnartigen Fallwindes der nordwestlichen Sierra Nevada de Santa Marta, Kolumbien. Mitt. Inst. Col.-Al. Invest. cient. 4, 83-95.

KATO, M., 1961. The distribution pattern of Hydrozoa on seaweed with some notes on the so-called coaction among hydrozoan species. Bull. mar. biol. Stn. Asamushi 10 (3), 195-202.

Kaufmann, R., 1967. Pegelaufzeichnungen am Rio Magdalena. Mitt. Inst. Col.-Al. Invest. cient. 1, 39-43.

Kinne, O., 1955. Uber den Einfluß des Salzgehaltes und der Temperatur auf Wachstum, Form and Vermehrung bei den Hydroidpolypen Cordylophora caspia (PALlAs), Thecata, Clavidae, Zool. Jb. (Allg. Zool. Physiol. Tiere) 66, 565-638.

- 1956. Zur Okologie der Hydroidpolypen des Nordostseekanals. Z. Morph. Okol. Tiere 45, 217-249.

Kührmann, D. H. H., 1974. The Coral Reefs of Cuba. Proc. second int. Coral Reef Symp. 2, 69-83.

LEwis, J. B., 1960. The fauna of the rocky shores of Barbados. Can. J. Zool. 38, 391-435.

Loeb, J. \& Ewald, W. F., 1914. Über die Gültigkeit des Bunsen-Roscoeschen Gesetzes für die heliotropische Erscheinung bei Tieren. Zentbl. Physiol. 27, 1165-1168.

Marktanner-Turneretscher, C., 1890. Die Hydroiden des k.k. naturhistorischen Hofmuseums. Ann. naturh. Mus. Wien 5, 195-286.

Mergner, H., 1967. Uber den Hydroidenbewuchs einiger Korallenriffe des Roten Meeres. Z. Morph. Okol. Tiere 60, 35-104.

- 1972. The influences of several ecological factors on the hydroid growth of some Jamaican Coral Cays. Proc. of the Sympos. on Corals and Coral Reefs (1969). Mar. biol. Ass. India, Mandapam, 275-290.

- \& Scherer, G., 1974. The physiographic zonation and the ecological conditions of some South Indian and Ceylon coral reefs. Proc. second int. Coral Reef Symp. 2, 3-30.

Morkyevski, O, B., 1960. Einige Studien, die die Faktoren der Zonierungen im oberen Litoralbereich kennzeichnen. Limnol. Oceanogr. 5, 389-396.

Müller-Cale, K. \& Krüger, E., 1913. Einige biologische Beobachtungen über die Entwicklung von Aglaophenia belleri, Aglaophenia pluma und Sertularella polyzonias. Mitt. Zool. Stn Neapel 21 (2), 4-50.

Nutting, C., 1900. American Hydroids. Part I. The Plumularidae. Spec. Bull. U.S. natn. Mus. $100(1), 1-285$.

- 1904. American Hydroids. Part II. The Sertularidae. Spec. Bull. U.S. natn. Mus. 100 (2), $1-325$.

- 1915. American Hydroids. Part III. The Campanularidae and the Bonneviellidae. Spec. Bull. U.S. natn. Mus. 100 (3), 1-126.

Prahm, C., 1972. Oberflächenströmungen, Salzgehalt und Temperatur an der Oberfläche. In: Westindien-Handbuch. Dt. Hydrograph. Inst., Hamburg, 1, 125-143.

Ralph, P. M. \& Thomson, H. G., 1968. Seasonal changes in growth of the erect stem of 
Obelia geniculata in Wellington Harbour, New Zealand. Zoology Publs. Vict. Univ. Wellington, 44, 1-21.

Riedi, R., 1959. Die Hydroiden des Golfes von Neapel und ihr Anteil an der Fauna der unterseeischen Höhlen. Ergebn. öst. Tyrrhenia-Exped. 16, 591-755.

- 1964a. Die Erscheinungen der Wasserbewegung und ihre Wirkung auf Sedentarier im mediterranen Felslitoral. Helgoländer wiss. Meeresunters. 10, 155-186.

- 1964b. 100 Jahre Litoralgliederung seir JOSEF LORENZ, neue und vergessene Gesichtspunkte. Int. Revue ges. Hydrobiol. 49, 281-305.

- 1966. Biologie der Meereshöhlen. Parey, Hamburg, 636 pp.

SOUTHWARD, A. J., 1958. The zonation of plants and animals on rocky seashores. Biol. Rev. 33, $137-177$.

Stechow, E., 1919. Zur Kenntnis der Hydroidenfauna des Mittelmeeres, Amerikas und anderer Gebiete. Teil I. Zool. Jb. (System. Okol. Geogr. Tiere) 42, 1-172.

- 1923. Zur Kenntnis der Hydroidenfauna des Mittelmeeres, Amerikas und anderer Gebiete. Teil II. Zool. Jb. (System. Okol. Geogr. Tiere) 47, 29-270.

Stephenson, T. A \& StepHENson, A., 1949. The universal features of zonation between tide-marks on rocky coasts. J. Ecol. 37, 289-305.

TARDENT, P., 1965. Ecological aspects of the morphodynamics of some Hydrozoa. Am. Zool. $5,525-529$.

Vannucci, M., 1946. Hydroida Thecaphora do Brasil. Archos. Zool. Est. S. Paulo, 4 (14), $535-598$.

- 1949. Hydrozoa do Brasil. Bolm. Fac. Filos. Ciēnc. Univ. S. Paulo (Zool.) 99 (14), 219-266.

Vervoort, W., 1968. Report on a collection of Hydroida from the Caribbean Region, including an annotated checklist of Caribbean hydroids. Zool. Verh., Leiden, 92, 1-124.

Wedler E., 1974a. Die Hydroiden der Cienaga Grande de Santa Marta und ciniges zu ihrer Okologie. Mitt. Inst. Cd.-Al. Invest. cient. 7, 31-39.

- 1974b. Zur Okologie der Hydroidpolypen aus dem tropischen Litoralgebiet der Umgebung von Santa Marta, Kolumbien. Diss. Bodum, 109 pp.

Williams, G. B., 1965. Observations on the behaviour of the planulae larvae Clatad squamata. J. mar. biol. Ass. U.K. 45, 257-273.

Anschrift des Autors: E. WEDLER

Lehrstuhl für Spezielle Zoologie

Ruhr-Universität Bochum

D-463 Bochum

Buscheystraße 